Ватиашвили М.P. Институт генетики

Тбилисского государственного университета им. И. Джавахишвили,

г. Тбилиси, Грузия.

kbloto@bk.ru

\title{
ИЗМЕНЕНИЕ РЕЖИМА ОСАДКОВ В РЕГИОНЕ ЦЕНТРАЛЬНОГО КАВКАЗА ПРИ ПРОВЕДЕНИИ ПРОТИВОГРАДОВОЙ ЗАЩИТЫ
}

Введение:

проведен обзор оценки влияния производственной противоградовой защиты сельскохозяйственных культур на режим осадков защищаемых и контрольных территорий, проводимой в регионе Центрального Кавказа с применением: артиллерийской и ракетной технологии засева; комбинированного метода, методов конкуренции, ускорения процесса осадкообразования и шокового воздействия.

\section{Материалы} и методы:

\section{Обсуждение и} заключения:

\section{Ключевые слова:}

многолетние опыты и отчеты по воздействию на прадовые процессы и искусственного увеличения осадков; фрагменты предотвращения и прерывания града; суммарные значения параметров воздействия и радиолокационных параметров облаков; метеорологические станции и радиолокаторы; комбинированный метод, методы конкуренции, ускорения процесса осадкообразования и шокового воздействия; непараметрические статистические методы.

оценка влияния методов противоградовой защиты на режим осадков исследуемой территории, многие из них решены в работах автора, защищены патентом и успешно применяются в противоградовой защите ВС Ставропольского края.

противоградовые ракеты, комбинированный метод, изменение режима осадков, защищаемые и контрольные территории. 
Vatiashvili M.R. The Institute of Genetics of Tbilisi State University named after

I. Dzhavakhishvili, Tbilisi, Georgia, kbloto@bk.ru

\section{THE ALTERATION OF ATMOSPHERIC PRECIPITATIONS MODE IN THE CENTRAL CAUCASUS REGION WHEN CARRYING OUT ANTI-HAIL PROTECTION ACTIVITIES}

Introduction: the review of evaluation of influence of production anti-hail protection of agricultural crops on the atmospheric precipitations mode of the protected and check-out areas, carried out in the Central Caucasus region with the application of: artillery and rocket seeding technology, combined method, competition as well as precipitating acceleration and shock impact methods, is made.

Materials and Methods: long-standing experiments and reports on affecting hail processes and manmade atmospheric precipitation augmentation; fragments of hail preventing and interrupting; total values of influence parameters and radar parameters of clouds; weather stations and radio-locators; combined method, competition as well as atmospheric precipitating acceleration and shock impact methods;

Discussion

and conclusions: nonparametric statistical methods.

the evaluation of influence of anti-hail protection methods on the atmospheric precipitations mode of the check-out area, many of them have been practically solved in author's works, patented and are successfully applied in antihail protection of the Stavropol krai paramilitary services.

Keywords: anti-hail rockets, combined method, the alteration of atmospheric precipitations mode, protected and check-out areas.

\section{Введение}

Градобития во многих регионах мира наносят существенный ущерб народному хозяйству, исчисляемый сотнями миллионов \$. К таковым относится и регион Центрального Кавказа, в котором по статистическим данным от града ежегодно погибало от 5 до 7\%, а в отдельные годы - до 15\% сельскохозяйственных (c/x) культур [2].

В исследуемом регионе, с целью уменьшения ущерба с/х культур от града, в 1967 г. начались производственные работы по противоградовой защите (ПГЗ) с/х культур $[2,3,15,17]$.

В южной части этого региона расположены защищаемые и контрольные территории (соответственно 3Т, $\mathrm{KT}_{1}$ и $\mathrm{KT}_{2}$ ) Военизированных служб (ВС) Южной и Восточной Грузии (рис. 1) [3, 15], а в северной его части (рис. 2) $\mathrm{KT}_{1}$, 3Т и $\mathrm{KT}_{2}$ ВС Краснодарского и Ставропольского краев, Кабардино-Балкарской и Карачаево-Черкесской республик и Республики Северная Осетия «Алания» (соответственно КрВС, СтВС и Северо-Кавказская ВС - СКВС) Госкомгидромета Российской Федерации (рис. 2) [2, 17].

Противоградовая защита с/х культур в:

- $\quad$ Южной Грузии осуществлялась комбинированным методом, с применением артиллерийской технологии засева [3]; Восточной Грузии - методом конкуренции, с приме- 


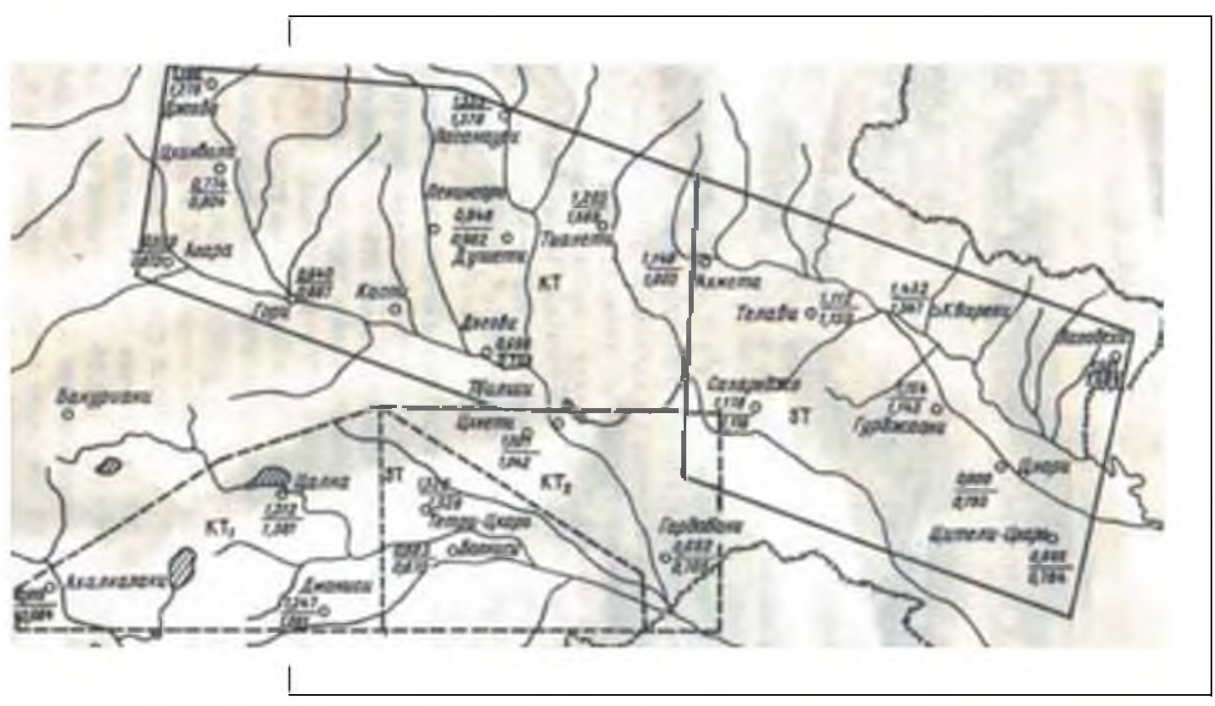

Puc. 1.

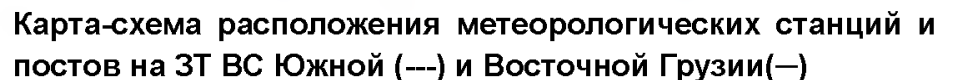

Fig. 1. Map-scheme of weather-stations and posts locations at the protected areas (PA) of paramilitary services (PS) of South and East Georgia

нением ракетной технологии засева [15]; Краснодарском крае, Кабардино-Балкарской и Карачаево-Черкесской республике и Республике Северная Осетия - Алания - методами конкуренции и ускорения процесса осадкообразования (УПО), с применением артиллерийской и ракетной технологии засева $[2,15]$; Ставропольском крае - методом шокового воздействия с применением ракетной технологии засева $[8,10,12]$.

Метод шокового воздействия включает в себя методики предотвращения и прерывания града на ЗТ и к подступам 3Т со стороны вторжения градовых облаков $[10,12]$. Данный метод:

не имеет аналога и отличается от существующих методов воздействия $[2,3,15,17]$ : научными концепциями и критериями засева, техническими средствами и технологиями засева, расходом количества реагентов, качеством реализации конщепций засева, методами оценки физической эффективности по воздействию на градовые процессы;

- $\quad$ становится причиной увеличения в Ставропольском крае физической и экономической эффективности ПГЗ от 60 до 


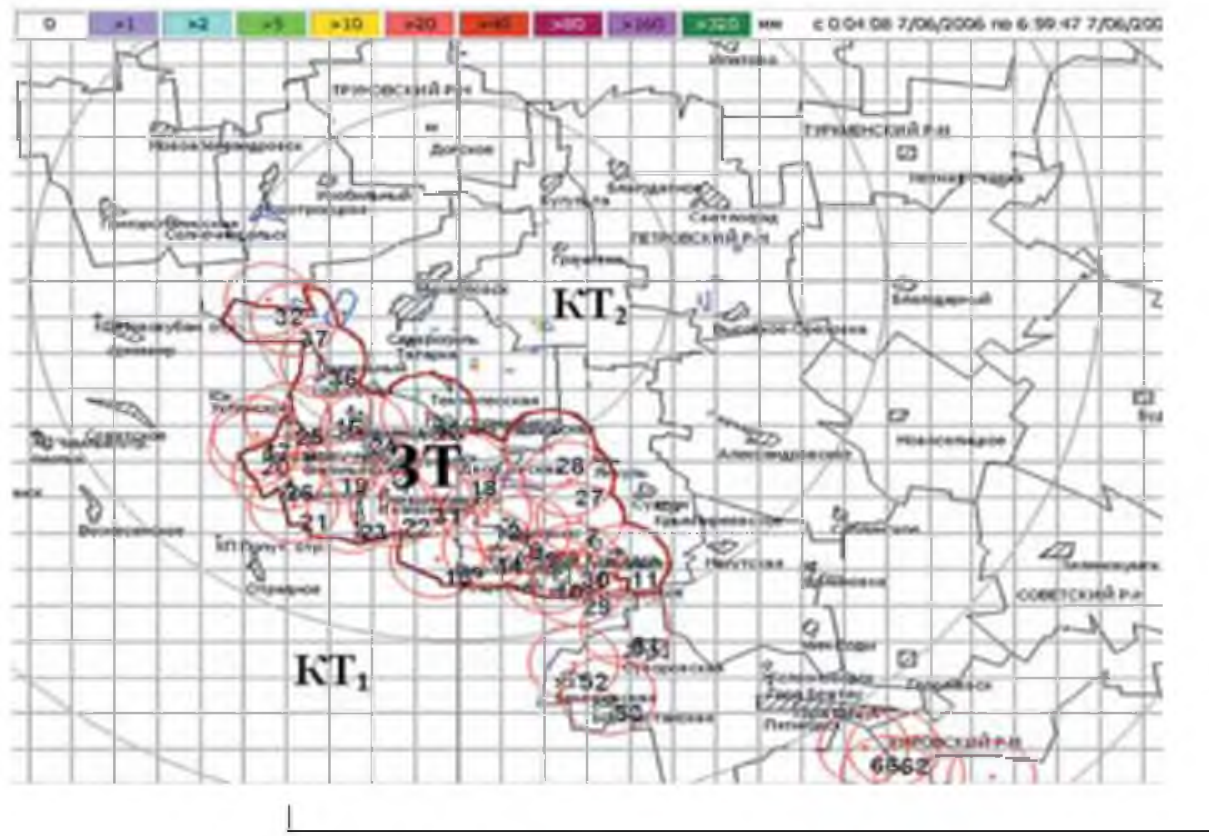

Рис. 2.

Карта-схема расположения ракетных пунктов воздействия на ЗТ ВС Ставропольского края

Fig. 2. Map-scheme of rocket stations location at PAs of the Stavropol krai PS.

$99 \%$ и работ по искусственному регулированию осадков (ИРО) от 10 до $15 \%$ [18].

Артиллерийская технология засева включает в себя пусковые установки (ПУ) «КС-19» и противоградовые снаряды (ПГС) «Эльбрус-2» и «Эльбрус-4», снаряженные, соответственно, частицами гигроскопического и кристаллизующего реагентов натрия хлора и йодистого серебра, соответственно, ЧГР $\mathrm{NaCl}$ и ЧКР $\mathrm{AgI}[2,3,17]$.

Ракетная технология засева включает в себя: ПУ «ТКБ-(04» и «ТКБ040» и противоградовые ракеты (ПГР) «Облако», типа «Алазань» и «Кристалл», которые снаряжались ЧКР AgI и йодистого свинща $\left(\mathrm{PbI}_{2}\right)[2,10,12.15]$.

В градоопасных и градовых облаках, являющихся соответственно объектами воздействия (ОВ) 1-2-й и 3-4-й категорий:

ЧКР AgI и $\mathrm{PbI} 2$ диспергировались в объемах зон роста града (РГ) и будущего градообразования (БГ) на уровнях изотерм минус $(6 \pm 3)^{\circ} \mathrm{C}$; ЧГР $\mathrm{NaCl}$ - в объемах теплой час- 
ти подоблачной и облачной атмосферы на уровнях изотерм $(15 \div 0){ }^{\circ} \mathrm{C}[2,3,15,17]$.

В конце 80-х годов двадцатого столетия, после 20-летнего периода проведения ПГЗ в регионе Центрального Кавказа, впервые был поставлен вопрос о том, какое влияние может оказать ПГЗ на режим осадков 3Т КТ1 и КТ2, расположенных соответственно с наветренной (КT1) и подветренной (КТ2) от 3Т стороны; и возможно ли при воздействии на градовые процессы добиться перераспределения осадков из зоны воздействия на $\mathrm{KT}_{1}$ и $\mathrm{KT}_{2}$ ?

Действительно, если активные воздействия на градовые процессы влияют на размер выпавшего града и динамику развития конвективного облака [9], то они должны оказать определенное влияние и на режим осадков $\mathrm{KT}_{1}, 3 \mathrm{~T}$ и КТ 2 исследуемого региона. Анализ литературных источников указывает на неоднозначность полученных результатов $[1,2,4-6]$ и необходимость проведения дальнейших исследований в этом направлении.

Целью работы является оценка влияния ПГЗ на режим осадков $\mathrm{KT}_{1}, 3 \mathrm{~T}$ и $\mathrm{KT}_{2}$ региона Центрального Кавказа, проводимая комбинированным методом, методами конкуренции, УПО и шокового воздействия.

\section{Материалы и методы исследования}

Материалами исследования послужили:

- $\quad$ многолетние опыты и отчеты по воздействию на градовые процессы и ИРО;

1-4-й категорий;

- $\quad$ суммарные значения радиолокационных параметров облаков и осадков (OO), включающих в себя: высоты верхней границы радиоэха облака за месяц ( $\Sigma \mathrm{Hв,} \mathrm{км/мес.),} \mathrm{радиоло-}$ кационные отражаемости ( $\Sigma Z /$ мес., $\Sigma d B Z /$ мес. и $\Sigma l g Z /$ мес.) и кинетические энергии градовых частищ облаков $(\Sigma E$, Дж $\left.\mathrm{m}^{2}\right)[6,11]$;

суммарные значения параметров воздействия, включающих в себя: количества израсходованных противоградовых снарядов и ракет $(\Sigma \mathrm{N}$, шт/мес.), продолжительности воздействия $(\Sigma \Delta \tau$, часы/мес.) в OB 1-4-й категорий, сопровождающихся осадками различной интенсивности, измеренными наземными метеорологическими станциями (НMC) и постами, неавтоматизированными и полуавтоматизированными («АСУ-МРЛ») метеорологическими радиолокаторами $[6,11]$; 
литературные источники оценки изменения режима осадков на КТ1, 3Т и КТ 2 до и в период проведения ПГЗ [1, 4-6].

Объем выборки на $\mathrm{KT}_{1}$, 3Т и $\mathrm{KT}_{2}$ Южной и Восточной Грузии для одномесячных (R1), двухмесячных $\left(R_{2}\right)$, трехмесячных $R_{3}$ и сезонных $\left(R_{4}\right)$ средних сумм осадков $(\mathrm{CCO})$ и модульных коэффициентов $\left(K_{1}-K_{4}\right)$ составляли соответственно 17, 34 и 51 экспериментальных единиц.

Для оценки влияния ПГЗ на режим ССО КТ1, ЗТ и КТ2 привлекался физико-статистический метод исследования, в основу которого положены непараметрические статистические методы, не требующие знания вида распределения осадков [16]. Метод предусматривает:

расчет $R_{1}-R_{4}$ и $K_{1}-K_{4}$ на $\mathrm{KT}_{1}, 3 \mathrm{~T}$ и $\mathrm{KT}_{2}$ исследуемой территории и оценку разности значений $\Delta R i$ и $\Delta K i(\mathrm{i}=1,2,3,4)$ до и в период проведения ПГЗ, указывающую на количественную оценку результатов ПГЗ;

- $\quad$ расчет по уравнениям исторической регрессии одномесячных, двухмесячных, трехмесячных и сезонных ССО $\left(R_{4}\right)$ на $\mathrm{KT}_{1}$, ЗТ и $\mathrm{KT}_{2}$ исследуемой территории, построенных по данным НМС до и в период проведения [5, 6];

- $\quad$ оценку разности между рассчитанными и фактическими $\mathrm{CCO}$ в годы проведения воздействий, характеризующей степень влияния ПГЗ на режим осадков $\mathrm{KT}_{1}$, ЗТ и $\mathrm{KT}_{2}$; оценку сушественности расхождения между ССО с помощью непараметрических методов, с применением критериев знаков $(\mathrm{X})$ и знако-рангового критерия Уилкоксона $(t)$ при числе экспериментальных единиц $n \leq 50$, а критерия $\chi_{2}-$ при $n>50[16]$.

\section{Результаты исследования}

В основу проведения ПГЗ и ИРО были положены различные реагенты, технологии засева, методы воздействия [2-6, 8-10, 12-14, 17, 18$]$.

\section{Оценка изменения режима осадков Южной Грузии комбинированным методом воздействия}

На рис. 1 представлены КТ 1 , 3Т и КТ 2 Южной Грузии, каждая из которых занимает площадь 350 тыс. га, а их протяженности по ведущему потоку не превышают 45 км. Проанализируем статистические характеристики значений $\left(R_{1}\right.$, мм/мес.) и модульных коэффициентов $\left(K_{1}, \%\right)$ на КТ 1 , ЗТ и $\mathrm{KT}_{2}$, Южной Грузии (табл. 1), включающих в себя их средние значения, среднеквадратические отклонения ( $\sigma$ ) и коэффициенты вариации (V) [5].

Из анализа таблицы 1 следует, что в годы проведения ПГЗ по сравнению с годами ее отсутствия в апреле-октябре: 


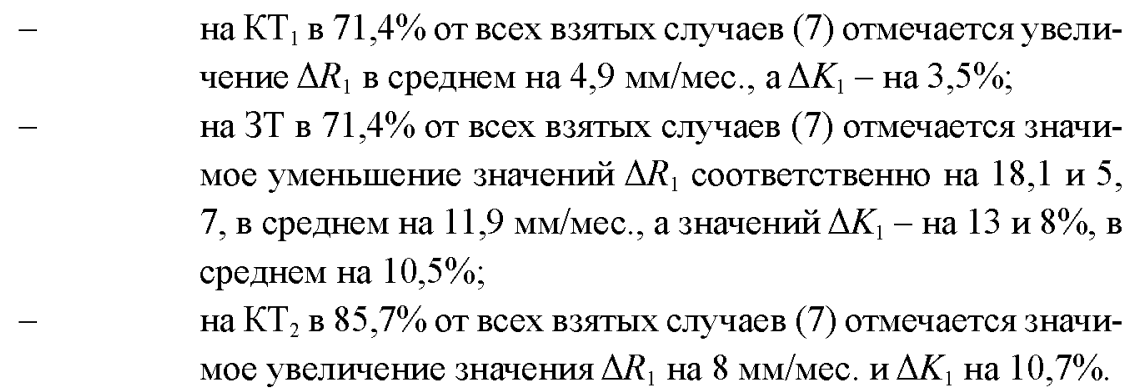

Анализ результатов влияния ПГЗ на режим осадков Южной

Грузии, представленный в табл. 1, позволил выявить, что в годы проведения ПГЗ значения $R_{1}$ и $K_{1}$ на $\mathrm{KT}_{1}$, как правило, выше чем в годы ее отсутствия, а на 3Т, наоборот, отмечается тенденция их уменьшения. Например, на ЗТ в апреле-августе и октябре отмечается уменьшение значений $\Delta K_{1}$ от 3 до $14 \%$, а в сентябре - наоборот его увеличение на $5 \%$ (уменьшение отмечено в $86 \%$ от всех взятых случаев - 7 месяцев).

Таблица 1. Результаты сравнения статистических характеристик значений одномесячных ссо ( $r_{1}$, мм) и модульных коэфффициентов $\left(\mathrm{\delta k}_{1}, \%\right)$ на КТ $1,3 \mathrm{~T}, \mathrm{KT}_{2}$ южной грузии до начала (1953-1966 гг.числитель) и в период проведения ПГЗ (1967-1983 гг. знаменатель)

Table 1. The results of comparison of statistical characteristics of one-month's average precipitation total $(\mathrm{apt})\left(\mathrm{r}_{1}, \mathrm{~mm}\right)$ and modular ratio $\left(\delta \mathrm{k}_{1}, \%\right)$ values at

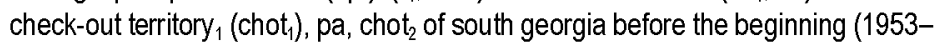
1966 - numerator) and during anti-hail protection (ahp) activities (1967-1983 denominator)

\begin{tabular}{|c|c|c|c|c|c|c|c|c|c|}
\hline \multirow[t]{2}{*}{ Месяц } & \multirow[t]{2}{*}{ Территория } & \multicolumn{2}{|l|}{$\mathrm{cco}$} & \multicolumn{2}{|c|}{$\begin{array}{l}\text { Среднеквадратическое } \\
\text { отклонение }\end{array}$} & \multicolumn{2}{|c|}{$\begin{array}{l}\text { Коэфрфиициент } \\
\text { вариации }\end{array}$} & \multicolumn{2}{|c|}{$\begin{array}{l}\text { Модульный } \\
\text { коэфрфициент }\end{array}$} \\
\hline & & $\mathbf{R}_{1}$ & $\Delta \mathrm{R}_{1}$ & $\sigma$ & $\Delta \sigma$ & v & $\Delta v$ & $K_{1}$ & $\Delta \mathrm{K}_{1} \cdot 100 \%$ \\
\hline \multirow[t]{3}{*}{ IV } & $k T_{1}$ & $\frac{67,6}{57,7}$ & $-9,9$ & $\frac{31,3}{18,2}$ & $-13,1$ & $\frac{0,46}{0,32}$ & $-0,14$ & $\frac{1,05}{1,05}$ & 0 \\
\hline & 3T & $\frac{72,7}{54,6}$ & $-18,1$ & $\frac{38,7}{21,6}$ & $-17,1$ & $\frac{0,53}{0,40}$ & $-0,13$ & $\frac{1,13}{1,00}$ & -13 \\
\hline & $k T_{2}$ & $\frac{52,1}{52,2}$ & 0,1 & $\frac{29,8}{18,2}$ & $-11,6$ & $\frac{0,57}{0,35}$ & $-0,22$ & $\frac{0,8}{0,95}$ & 15 \\
\hline \multirow[t]{3}{*}{ V } & $k T_{1}$ & $\frac{98,9}{107,6}$ & 8,7 & $\frac{49,8}{40,3}$ & $-9,5$ & $\frac{0,5}{0,37}$ & $-0,13$ & $\frac{1,22}{2,22}$ & 0 \\
\hline & $3 T$ & $\frac{82,1}{82,4}$ & 0,3 & $\frac{44,3}{31,8}$ & $-12,5$ & $\frac{0,54}{0,36}$ & $-0,18$ & $\frac{1,01}{0,94}$ & -7 \\
\hline & $\mathrm{KT}_{2}$ & $\frac{62,3}{74,0}$ & 11,7 & $\frac{35,6}{27,8}$ & $-7,8$ & $\frac{0,57}{0,38}$ & $-0,19$ & $\frac{0,78}{0,84}$ & 6 \\
\hline
\end{tabular}




\begin{tabular}{|c|c|c|c|c|c|c|c|c|c|}
\hline \multirow[t]{2}{*}{ Месяц } & \multirow[t]{2}{*}{ Территория } & \multicolumn{2}{|l|}{ cco } & \multicolumn{2}{|c|}{$\begin{array}{l}\text { Среднеквадратическое } \\
\text { отклонение }\end{array}$} & \multicolumn{2}{|c|}{$\begin{array}{l}\text { Коэсрфициент } \\
\text { вариации }\end{array}$} & \multicolumn{2}{|c|}{$\begin{array}{l}\text { Модульный } \\
\text { коэфрфициент }\end{array}$} \\
\hline & & $\mathbf{R}_{1}$ & $\Delta R_{1}$ & $\sigma$ & $\Delta \sigma$ & $v$ & $\Delta \mathrm{V}$ & $K_{1}$ & $\Delta K_{1} \cdot 100 \%$ \\
\hline \multirow[t]{3}{*}{ VI } & $\mathrm{KT}_{1}$ & $\frac{92,8}{102,0}$ & 9,2 & $\frac{29,9}{27,2}$ & $-2,7$ & $\frac{0,32}{0,26}$ & $-0,06$ & $\frac{1,19}{1,16}$ & -3 \\
\hline & $3 T$ & $\frac{82,5}{84,0}$ & 1,5 & $\frac{40,0}{33,5}$ & $-6,5$ & $\frac{0,49}{0,40}$ & $-0,09$ & $\frac{1,06}{0,96}$ & -10 \\
\hline & $\mathrm{KT}_{2}$ & $\frac{58,5}{76,8}$ & 18,3 & $\frac{27,4}{40,5}$ & 13,1 & $\frac{0,47}{0,53}$ & 0,06 & $\frac{0,75}{0,88}$ & 13 \\
\hline \multirow[t]{3}{*}{ VII } & $\mathrm{KT}_{1}$ & $\frac{65,5}{63,0}$ & $-2,5$ & $\frac{32,0}{27,4}$ & $-4,6$ & $\frac{0,49}{0,43}$ & $-0,06$ & $\frac{1,17}{1,16}$ & -1 \\
\hline & $3 T$ & $\frac{58,8}{52,6}$ & $-6,2$ & $\frac{41,3}{31,4}$ & $-9,9$ & $\frac{0,71}{0,60}$ & $-0,11$ & $\frac{1,04}{0,96}$ & -8 \\
\hline & $\mathrm{KT}_{2}$ & $\frac{43,6}{47,5}$ & 3,9 & $\frac{25,8}{25,6}$ & $-0,2$ & $\frac{0,59}{0,54}$ & $-0,05$ & $\frac{0,87}{0,78}$ & 9 \\
\hline \multirow[t]{3}{*}{ VIII } & $\mathrm{KT}_{1}$ & $\frac{55,4}{69,2}$ & 13,8 & $\frac{16,8}{34,1}$ & 17,3 & $\frac{0,30}{0,49}$ & 0,19 & $\frac{1,19}{1,34}$ & 15 \\
\hline & $3 T$ & $\frac{42,3}{49,1}$ & 6,8 & $\frac{35,4}{30,0}$ & $-5,4$ & $\frac{0,80}{0,61}$ & $-0,19$ & $\frac{0,91}{0,88}$ & -3 \\
\hline & $\mathrm{KT}_{2}$ & $\frac{41,6}{48,9}$ & 7,3 & $\frac{43,0}{34,9}$ & $-8,1$ & $\frac{1,00}{0,71}$ & $-0,29$ & $\frac{0,90}{0,88}$ & -2 \\
\hline \multirow[t]{3}{*}{ IX } & $\mathrm{KT}_{1}$ & $\frac{54,1}{56,6}$ & 2,5 & $\frac{30,5}{34,6}$ & 4,1 & $\frac{0,15}{0,61}$ & 0,46 & $\frac{1,20}{1,21}$ & 1 \\
\hline & $3 T$ & $\frac{47,4}{49,8}$ & 2,4 & $\frac{27,9}{37,0}$ & 9,1 & $\frac{0,16}{0,64}$ & 0,48 & $\frac{0,95}{1,00}$ & 5 \\
\hline & $\mathrm{KT}_{2}$ & $\frac{33,4}{43,2}$ & 9,8 & $\frac{22,3}{31,6}$ & 9,3 & $\frac{0,20}{0,73}$ & 0,53 & $\frac{0,67}{0,87}$ & 20 \\
\hline \multirow[t]{3}{*}{$x$} & $\mathrm{KT}_{1}$ & $\frac{35,3}{46,5}$ & 11,2 & $\frac{20,6}{21,2}$ & 0,6 & $\frac{0,59}{0,51}$ & $-0,08$ & $\frac{1,02}{1,16}$ & 14 \\
\hline & $3 T$ & $\frac{37,5}{37,6}$ & 0,1 & $\frac{21,6}{19,0}$ & $-2,6$ & $\frac{0,58}{0,51}$ & $-0,07$ & $\frac{1,08}{0,94}$ & -14 \\
\hline & $\mathrm{KT}_{2}$ & $\frac{31,0}{36,0}$ & 5,0 & $\frac{19,7}{21,8}$ & 2,1 & $\frac{0,63}{0,60}$ & $-0,03$ & $\frac{0,90}{0,90}$ & 0 \\
\hline
\end{tabular}

Уменьшение значений $\Delta K_{1}$ на $3 \mathrm{~T}$ по сравнению $\mathrm{KT}_{1}$ и $\mathrm{KT}_{2}$ в апреле достигает $20,5 \%$, а июле $-12,0 \%$. На $\mathrm{KT}_{2}$, расположенной с подветренной от $3 \mathrm{~T}$ стороны в эти же месяцы, наоборот, отмечается их увеличение соответственно на 15,0 и $9,0 \%$. Уменьшение $\Delta R_{1}$ и $\Delta K_{1}$ на 3Т подтверждается таюже и результатами сравнения значений разностей среднеквадратических отклонений $(\Delta \sigma)$ и коэффициентов вариации $(\Delta V)$. 
Таблица 2. Результаты сравнения статистических характеристик значений

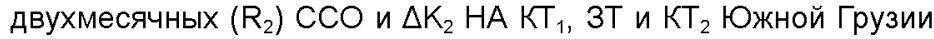
до начала и в период проведения ПГЗ (соответственно 19531966 гг. - числитель, 1967-1983 гг. - знаменатель)

Table 2. The results of comparison of statistical characteristics of two-months' apt $\left(\mathrm{R}_{2}\right)$ and $\Delta \mathrm{K}_{2}$ values at $\mathrm{ChOT}_{1}, \mathrm{PA}, \mathrm{ChOT}_{2}$ of South Georgia before the beginning and during ahp activities (correspondingly 1953-1966 - numerator; 1967-1983 denominator)

\begin{tabular}{|c|c|c|c|c|c|c|c|c|c|}
\hline \multirow[t]{2}{*}{ Месяц } & \multirow[t]{2}{*}{ Территория } & \multicolumn{2}{|l|}{$\mathrm{cco}$} & \multicolumn{2}{|c|}{$\begin{array}{l}\text { Среднеквадратическое } \\
\text { отклонение }\end{array}$} & \multicolumn{2}{|c|}{$\begin{array}{l}\text { Коэфрфицииент } \\
\text { вариации }\end{array}$} & \multicolumn{2}{|c|}{$\begin{array}{l}\text { Модульный } \\
\text { коэффрициент }\end{array}$} \\
\hline & & $R_{2}$ & $\Delta R_{2}$ & $\sigma$ & $\Delta \sigma$ & $v$ & $\Delta V$ & $K_{2}$ & $\Delta K_{2} \cdot 100 \%$ \\
\hline \multirow[t]{3}{*}{ IV-V } & $\mathrm{KT}_{1}$ & $\frac{166,6}{165,5}$ & $-1,1$ & $\frac{87,6}{79,8}$ & $-7,8$ & $\frac{0,53}{0,48}$ & $-0,05$ & $\frac{1,15}{1,16}$ & -1 \\
\hline & $3 \mathrm{~T}$ & $\frac{154,8}{142,8}$ & $-12,0$ & $\frac{82,2}{63,4}$ & $-18,8$ & $\frac{0,53}{0,44}$ & $-0,09$ & $\frac{1,06}{0,99}$ & -7 \\
\hline & $\mathrm{KT}_{2}$ & $\frac{114,4}{126,2}$ & 11,8 & $\frac{65,2}{51,2}$ & $-14,0$ & $\frac{0,57}{0,41}$ & $-0,16$ & $\frac{0,79}{0,87}$ & 8 \\
\hline \multirow[t]{3}{*}{ VI-VII } & $\mathrm{KT}_{1}$ & $\frac{158,4}{167,5}$ & 9,1 & $\frac{66,8}{67,6}$ & 0,8 & $\frac{0,42}{0,40}$ & $-0,02$ & $\frac{1,19}{1,17}$ & -2 \\
\hline & $3 T$ & $\frac{140,2}{136,7}$ & $-3,5$ & $\frac{83,4}{71,4}$ & $-12,0$ & $\frac{0,59}{0,52}$ & $-0,07$ & $\frac{1,05}{0,96}$ & -9 \\
\hline & $\mathrm{KT}_{2}$ & $\frac{102,2}{124,3}$ & 22,1 & $\frac{54,3}{73,2}$ & 18,9 & $\frac{0,53}{0,59}$ & 0,06 & $\frac{0,78}{0,87}$ & 9 \\
\hline \multirow[t]{3}{*}{ VIII-IX } & $\mathrm{KT}_{1}$ & $\frac{144,6}{172,3}$ & 27,7 & $\frac{73,8}{94,2}$ & 20,4 & $\frac{0,51}{0,55}$ & 0,04 & $\frac{1,15}{1,18}$ & 3 \\
\hline & $3 \mathrm{~T}$ & $\frac{127,2}{136,5}$ & 9,3 & $\frac{85,2}{82,8}$ & $-2,4$ & $\frac{0,67}{0,61}$ & $-0,06$ & $\frac{1,01}{0,94}$ & -7 \\
\hline & $\mathrm{KT}_{2}$ & $\frac{105,9}{128,1}$ & 22,2 & $\frac{89,4}{89,4}$ & 0,0 & $\frac{0,84}{0,70}$ & $-0,14$ & $\frac{1,04}{1,08}$ & 4 \\
\hline
\end{tabular}

Более информативными оказались двухмесячные, трехмесячные и сезонные значения осадков и модульных коэффициентов (соответственно $R_{2}$, мм/мес. и $\Delta K_{2}, \% ; R_{3}$, мм/мес. и $\Delta K_{3}, \% ; R_{4}$, мм/мес. и $\Delta K 4, \%$ ), измеренные на $\mathrm{KT}_{1}$, 3Т и $\mathrm{KT}_{2}$ Южной Грузии до начала и в период проведения ПГЗ. Они представлены в таблицах 2-5.

Из анализа:

таблицы 2 следует, что в период проведения ПГЗ по сравнению с периодом ее отсутствия на ЗТ отмечается уменьшение значений двухмесячных $\mathrm{CCO}$ (апрель-май) $\Delta R_{2}$ на $12,0 \mathrm{~mm} /$ мес. и $\Delta K_{2}$ на $7 \%$, а на $\mathrm{KT}_{2}-$ их увеличение соответственно на 11,8 мм/мес. и $8 \%$; 
Таблица 3. Результаты сравнения статистических характеристик значений трехмесячных CCO $\left(R_{3}\right)$ и $\Delta K_{3}$ на $K T_{1}$, ЗТ и $K T_{2}$ Южной Грузии до начала и в период проведения ПГЗ (соответственно 19531966 гг. - числитель, 1967-1983 гг. - знаменатель)

Table 3. The results of comparison of statistical characteristics of three-months' apt $\left(\mathrm{R}_{3}\right)$ and $\triangle \mathrm{K}_{3}$ VALUES AT $\mathrm{ChOT}_{1}, \mathrm{PA}$ and $\mathrm{ChOT}_{2}$ of South Georgia before the beginning and during ahp activities (correspondingly 1953-1966 - numerator; 1967-1983 - denominator)

\begin{tabular}{|c|c|c|c|c|c|c|c|c|c|}
\hline \multirow[t]{2}{*}{ Месяц } & \multirow[t]{2}{*}{ Территория } & \multicolumn{2}{|l|}{$\mathrm{cco}$} & \multicolumn{2}{|c|}{$\begin{array}{l}\text { Среднеквадратическое } \\
\text { отклонение }\end{array}$} & \multicolumn{2}{|c|}{$\begin{array}{l}\text { Коэрффициент } \\
\text { вариации }\end{array}$} & \multicolumn{2}{|c|}{$\begin{array}{l}\text { Модульный } \\
\text { коэфрфиициент }\end{array}$} \\
\hline & & $R_{3}$ & $\Delta R_{3}$ & $\sigma$ & $\Delta \sigma$ & $v$ & $\Delta V$ & $K_{3}$ & $\Delta K_{3} \cdot 100 \%$ \\
\hline \multirow[t]{3}{*}{$|V-V|$} & $K \mathrm{~T}_{1}$ & $\frac{259,2}{269,4}$ & 10,2 & $\frac{118,8}{111,9}$ & $-6,9$ & $\frac{0,46}{0,43}$ & $-0,03$ & $\frac{1,16}{1,16}$ & 0 \\
\hline & $3 T$ & $\frac{236,4}{226,8}$ & $-9,6$ & $\frac{120,9}{97,8}$ & $-23,1$ & $\frac{0,51}{0,43}$ & $-0,08$ & $\frac{1,06}{0,97}$ & -9 \\
\hline & $\mathrm{K} \mathrm{T}_{2}$ & $\frac{172,8}{202,8}$ & 30,0 & $\frac{91,8}{95,1}$ & 3,3 & $\frac{0,53}{0,47}$ & $-0,06$ & $\frac{0,78}{0,87}$ & 9 \\
\hline \multirow[t]{3}{*}{ VII-IX } & $K T_{1}$ & $\frac{174,6}{189,3}$ & 14,7 & $\frac{81,3}{95,7}$ & 14,4 & $\frac{0,46}{0,51}$ & 0,05 & $\frac{1,19}{1,18}$ & -1 \\
\hline & $3 T$ & $\frac{147,9}{151,5}$ & 3,6 & $\frac{105,3}{91,8}$ & $-13,5$ & $\frac{0,71}{0,61}$ & $-0,10$ & $\frac{1,01}{0,95}$ & -6 \\
\hline & $\mathrm{K} \mathrm{T}_{2}$ & $\frac{118,2}{139,8}$ & 21,6 & $\frac{93,6}{91,2}$ & $-2,4$ & $\frac{0,79}{0,65}$ & $-0,14$ & $\frac{0,80}{0,87}$ & 7 \\
\hline
\end{tabular}

Таблица 4.

Результаты сравнения статистических характеристик значений сезонных (IV-X) $\Delta R_{\mathrm{c}}$ (Mm/Mес.) и $\Delta K_{\mathrm{c}}(\%) \mathrm{CCO}$ на $\mathrm{KT}_{1}, 3 \mathrm{~T}_{1} \mathrm{KT}_{2}$ Южной Грузии до начала (1953-1966 гг. - числитель) и в период проведения ПГЗ (1967-1983 гг. - знаменатель)

Table 4. The results of comparison of statistical characteristics of seasonal (IV-X) $\Delta R_{\mathrm{S}}(\mathrm{mm} / \mathrm{mth})$ and $\Delta K_{\mathrm{S}}(\%)$ values of apt at $\mathrm{ChOT}_{1}$, $\mathrm{PA}, \mathrm{ChOT}_{2}$ of South Georgia before the beginning (1953-1966 numerator) and during ahp activities (1967-1983 - denominator)

\begin{tabular}{|c|c|c|c|c|c|c|c|c|}
\hline \multirow[t]{2}{*}{$\begin{array}{l}\text { Teppn- } \\
\text { тория }\end{array}$} & \multicolumn{2}{|l|}{$\mathrm{cco}$} & \multicolumn{2}{|c|}{$\begin{array}{l}\text { Среднеквадратическое } \\
\text { отклонение }\end{array}$} & \multicolumn{2}{|c|}{$\begin{array}{l}\text { Коэфорициент } \\
\text { вариации }\end{array}$} & \multicolumn{2}{|c|}{$\begin{array}{l}\text { Модульный } \\
\text { коэфороициент }\end{array}$} \\
\hline & $\mathrm{Rc}$ & $\Delta R c$ & $\sigma$ & $\Delta \sigma$ & $v$ & $\Delta v$ & Kc & $\Delta K \mathrm{c} \cdot 100 \%$ \\
\hline$K T_{1}$ & $\frac{464}{504}$ & 40 & $\frac{121}{76}$ & -45 & $\frac{0,21}{0,12}$ & $-0,09$ & $\frac{1,114}{1,172}$ & 5,8 \\
\hline 3T & $\frac{430}{413}$ & -17 & $\frac{154}{87}$ & -67 & $\frac{0,28}{0,19}$ & $-0,09$ & $\frac{1,032}{0,964}$ & $-6,8$ \\
\hline $\mathrm{K} \mathrm{T}_{2}$ & $\frac{337}{371}$ & 34 & $\frac{137}{79}$ & -58 & $\frac{0,28}{0,16}$ & $-0,12$ & $\frac{0,807}{0,862}$ & 5,5 \\
\hline
\end{tabular}




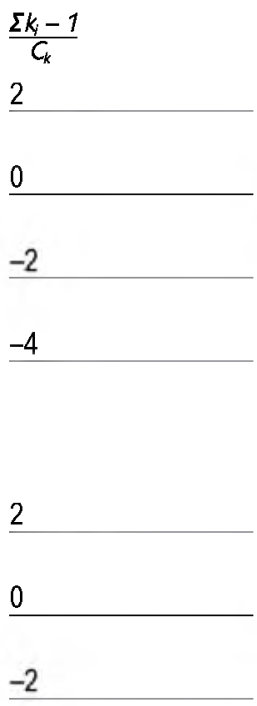

Рис. 3.

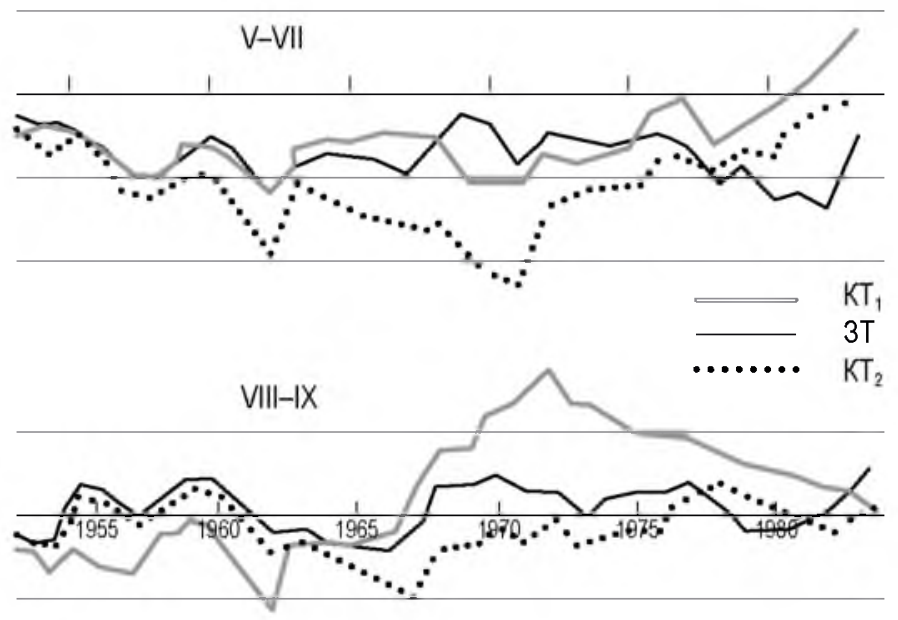

Вековое распределение значений $\Sigma K_{1}-1 / c_{\text {ri }}$ на $\mathrm{KT}_{1}$, 3Т и $\mathrm{KT}_{2}$ Южной Грузии до начала (1953-1966 гг.) и период (19671983 гг.) проведения ПГЗ.

Fig. 3. A secular values distribution $\Sigma K_{1}-1 / c_{n}$ at ChOT1, PA and ChOT2 of South Georgia before the beginning (1953-1966) and during (1967-1983) AHP activities.

таблицы 3 следует, что в период проведения ПГЗ по сравнению с периодом ее отсутствия на 3Т отмечается уменьшение значений трехмесячных (IV-VI) $\mathrm{CCO}\left(\Delta R_{3}\right)$ на 9,6 мм/ мес. и $\Delta K_{3}$ на $9 \%$, а на $\mathrm{KT}_{2}$ - их увеличение соответственно на 30 мм/мес. и $9 \%$;

- $\quad$ таблицы 4 следует, что в период проведения ПГЗ по сравнению с периодом ее отсутствия на $3 Т$ отмечается уменьшение значений сезонных (IV-X) $\mathrm{CCO} \Delta R_{4}$ на $17 \mathrm{~mm} / \mathrm{mec.}$ и $\Delta K_{4}$ на $7,1 \%$, а на $\mathrm{KT}_{2}-$ их увеличение соответственно на $34 \mathrm{мм} / \mathrm{Mес.} \mathrm{и} 5,5 \%$.

Полученные выше выводы дополнительно проверялись с помощью уравнений исторической регрессии, представленных в таблице 5 [5]. Из этой таблицы видно, что:

в апреле-мае, июне-июле, августе-сентябре на ЗТ отмечается статистически значимое уменьшение $\mathrm{CCO}$, соответственно на $13,1,16,2$ и $8,1 \%$, а на $\mathrm{KT}_{2}$ - их увеличение, соответственно на $14,9,21,2$ и 9,2\%; 
в апреле-июне на ЗТ отмечается значимое уменьшение ССО до $14,2 \%$, а на $\mathrm{KT}_{2}$ - их увеличение до $20,2 \%$.

Различия существенны при $\alpha=0,05, n=51, \chi_{\mathrm{p}}^{2}=12,2>\chi_{\text {таб̆ }}^{2}=3,8$ [16].

Во второй половине теплого периода года, включающего июль-сентябрь, на ЗТ также отмечается 10,6-процентное уменьшение, а на $\mathrm{KT}_{2}-$ 12,2-процентное увеличение ССО. Расхождение между средними оказались не существенными, так как при $\alpha=0,05, n=51, \chi_{\mathrm{p}}^{2}=0,7 \leq \chi_{\text {таб̆ }}^{2}=3,8$.

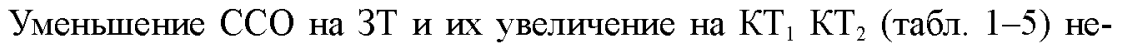
возможно объяснить синоптическими процессами и физико-географическими условиями и, по всей видимости, вызвано влиянием ПГЗ. Она может оказать существенное влияние и на величину коэффициента корреляции. Если до начала ПГЗ коэффициенты корреляции между СCO 3Т и $\mathrm{KT}_{1}, 3 \mathrm{~T}$ и $\mathrm{KT}_{2}$, $\mathrm{KT}_{1}$ и КТ 2 Южной Грузии соответственно были равны $0,94 \pm 0,05,0,92 \pm 0,05$, $0,82 \pm 0,05$, то в период ее проведения они уменьшились до $0,80,0,78$ и 0,81 . При уровне значимости $\alpha=0,001$ и числе степеней свободы $n=9$ последние 3 коэффициента корреляции оказались статистически необеспеченными, приводящими к нарушению корреляционных связей между осадками защищаемых и контрольных территорий Южной Грузии.

Получение избыточной влаги на $\mathrm{KT}_{2}$ (табл. 1-5) по сравнению с влагой на ЗТ Южной Грузии, по всей видимости, связано не только с перераспределением осадков из зоны воздействия на КТ 2 , но их стимулированием при воздействии на градовые процессы гигроскопическим и кристаллизующим реагентами [6].

Чтобы убедиться в достоверности полученных результатов проанализируем вековое распределение разностной интегральной кривой значений модульных коэффициентов $\left(\sum K_{i}-1 / C_{v i}\right)$ трехмесячных (V-VII) и двухмесячных (VIII-IX) CCO на КT 1 , 3Т и КТ 2 Южной Грузии до (1953-1966 гг.) и период (1967-1983 гг.) проведения ПГЗ (рис. 3). Из этого рисунка видно, что если до начала ПГЗ средние значения $\sum K_{i}-1 / C_{v i}$ на ЗТ, в целом, превалировали над $\mathrm{KT}_{1}$ и $\mathrm{KT}_{2}$, то в годы проведения воздействий наблюдается обратная картина.

Подтверждением могут служить графики на рисунке 4, на котором для мая-июля приводятся сравнения значений фактических осадков, наблюдаемых в годы проведения ПГЗ на ЗТ и $\mathrm{KT}_{2}$, с таковыми, рассчитанными по уравнениям регрессии (табл. 5).

Из рисунка 4 видно, что на 3 Ф фактические осадки в $74 \%$ всех случаев оказались меньше рассчитанных. Они расположены ниже прямой линии, проведенной под углом $45^{\circ}$. На КТ 2 - наоборот, в $71 \%$ всех случаев фактические осадки оказались расположенными выше линии регрессии. Таким образом, выявляется факт перераспределения осадков при проведении ПГЗ.

С целью объяснения физической сущности наблюдаемого эффекта были проанализированы суммарные трехмесячные значения: 
Таблица 5.

Оценка влияния ПГЗ на режим ССО КТ 13 З в КТ 2 Южной Грузии с помощью «Метода исторической регрессии»

Table 5. The evaluation of AHP influence on APT mode of $\mathrm{ChOT}_{1}, \mathrm{PA}_{\text {and }} \mathrm{ChOT}_{2}$ of South Georgia with the help of «Historical regression method»)

\begin{tabular}{|c|c|c|c|c|c|c|c|}
\hline Месяц & \multicolumn{5}{|c|}{ Уравнение регрессии } & \multicolumn{2}{|c|}{$\mathbf{r}$} \\
\hline IV-V & \multicolumn{5}{|c|}{$\begin{array}{l}R_{3 \mathrm{~T}}=0,28 R_{\mathrm{KT}_{1}}+0,48 R_{\mathrm{KT}_{2}}+31,5 \\
R_{\mathrm{KT}_{2}}=0,60 R_{\mathrm{3T}}+0,13 R_{\mathrm{KT}_{1}}-1,0\end{array}$} & \multicolumn{2}{|c|}{$\begin{array}{l}0,91 \\
0,90\end{array}$} \\
\hline VI-VII & \multicolumn{5}{|c|}{$\begin{array}{l}R_{\mathrm{3T}}=0,60 R_{\mathrm{KT}_{1}}+0,77 R_{\mathrm{KT}_{2}}-81,8 \\
R_{\mathrm{KT}_{2}}=0,52 R_{3 \mathrm{~T}}+0,08 R_{\mathrm{KT}_{1}}+44,0\end{array}$} & \multicolumn{2}{|c|}{$\begin{array}{l}0,92 \\
0,87\end{array}$} \\
\hline VIII-IX & \multicolumn{5}{|c|}{$\begin{array}{l}R_{3 \mathrm{~T}}=0,18 R_{\mathrm{KT}_{1}}+0,77 R_{\mathrm{KT}_{2}}+31,5 \\
R_{\mathrm{KT}_{2}}=0,96 R_{\mathrm{3T}}+0,04 R_{\mathrm{KT}_{1}}-40,4\end{array}$} & \multicolumn{2}{|c|}{$\begin{array}{l}0,91 \\
0,90\end{array}$} \\
\hline$|\mathrm{V}-\mathrm{V}|$ & \multicolumn{5}{|c|}{$\begin{array}{l}R_{3 \mathrm{~T}}=0,35 R_{\mathrm{KT}_{1}}+0,80 R_{\mathrm{KT}_{2}}+120 \\
R_{\mathrm{KT}_{2}}=0,56 R_{3 \mathrm{~T}}+0,13 R_{\mathrm{KT}_{1}}+12,1\end{array}$} & \multicolumn{2}{|c|}{$\begin{array}{l}0,87 \\
0,87\end{array}$} \\
\hline VII-IX & \multicolumn{5}{|c|}{$\begin{array}{l}R_{3 \mathrm{~T}}=0,42 R_{\mathrm{KT}_{1}}+0,75 R_{\mathrm{KT}_{2}}-25,2 \\
R_{\mathrm{KT}_{2}}=0,82 R_{3 \mathrm{~T}}+0,05 R_{\mathrm{KT}_{1}}+10,0\end{array}$} & \multicolumn{2}{|c|}{$\begin{array}{l}0,92 \\
0,88\end{array}$} \\
\hline \multirow[t]{2}{*}{ Месяц } & \multicolumn{4}{|c|}{ Количество осадков, мм } & \multicolumn{3}{|c|}{ Критерий } \\
\hline & $\delta$ & $R_{\mathrm{p}}$ & $R_{\phi}-R_{\mathrm{p}}$ & $\frac{R_{\phi}-R_{\mathrm{p}}}{R_{\phi}} \times 100 \%$ & $x_{\mathrm{p}}$ & $t_{\mathrm{p}}$ & $x^{2}$ \\
\hline IV-V & $\begin{array}{l}16,6 \\
14,1\end{array}$ & $\begin{array}{l}164,4 \\
109,9\end{array}$ & $\begin{array}{l}-21,6 \\
16,4\end{array}$ & $\begin{array}{l}-13,1 \\
14,9\end{array}$ & $\begin{array}{l}27 \\
25\end{array}$ & $\begin{array}{l}122 \\
-133\end{array}$ & - \\
\hline VI-VII & $\begin{array}{l}16,6 \\
13,6\end{array}$ & $\begin{array}{l}163,0 \\
102,1\end{array}$ & $\begin{array}{l}-26,4 \\
21,7\end{array}$ & $\begin{array}{l}-16,2 \\
21,2\end{array}$ & $\begin{array}{l}-25 \\
23\end{array}$ & $\begin{array}{l}145 \\
-171\end{array}$ & - \\
\hline VIII-IX & $\begin{array}{l}12,9 \\
14,4\end{array}$ & $\begin{array}{l}107,6 \\
84,3\end{array}$ & $\begin{array}{l}-8,8 \\
7,8\end{array}$ & $\begin{array}{l}-8,1 \\
9,2\end{array}$ & $\begin{array}{l}-22 \\
23\end{array}$ & $\begin{array}{l}184 \\
-175\end{array}$ & - \\
\hline$|\mathrm{V}-\mathrm{V}|$ & $\begin{array}{l}20,1 \\
15,2\end{array}$ & $\begin{array}{l}264,3 \\
169,0\end{array}$ & $\begin{array}{l}-37,5 \\
34,1\end{array}$ & $\begin{array}{l}-14,2 \\
20,2\end{array}$ & - & - & $\begin{array}{l}12,2 \\
-9,5\end{array}$ \\
\hline VII-IX & $\begin{array}{l}15,9 \\
14,6\end{array}$ & $\begin{array}{l}169,5 \\
124,5\end{array}$ & $\begin{array}{l}-18,0 \\
15,2\end{array}$ & $\begin{array}{l}-10,6 \\
12,0\end{array}$ & $\begin{array}{l}- \\
-\end{array}$ & $\begin{array}{l}- \\
-\end{array}$ & $\begin{array}{l}0,7 \\
0,2\end{array}$ \\
\hline
\end{tabular}

радиолокационных параметров, включающих в себя логарифмы радиолокационной отражаемости ( $\Sigma \lg Z, \mathrm{dBZ})[6,11]$ и высот верхней границы радиоэха облака $\left(\Sigma H_{\mathrm{B}}, \mathbf{\kappa м}\right)$, прямо и косвенно характеризующие его водозапасы;

параметров воздействия, включающих в себя противоградовые изделия ( $\Sigma N$, шт.) «Эльбрус-2» и «Эльбрус-4», соответственно снаряженные ЧГР $\mathrm{NaCl}$ и ЧКР AgI и продолжительности воздействий $(\Sigma \Delta \tau$, ч.) на ОВ 1-4-й категорий. 

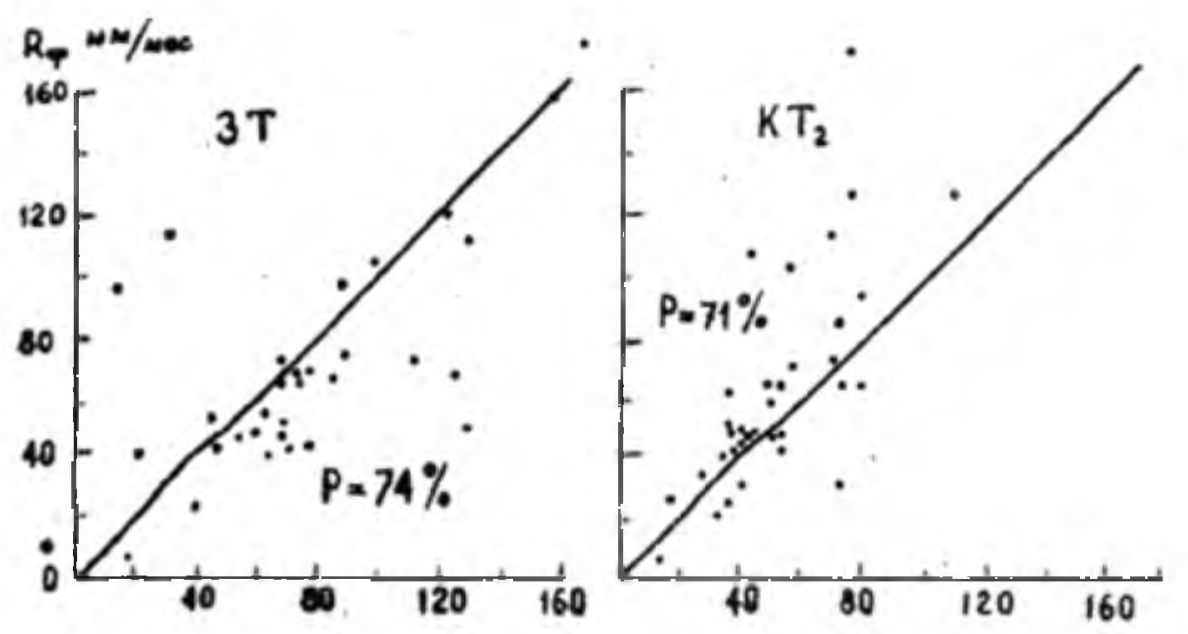

Рис. 4. Сравнение рассчитанных и фактически наблюдаемых на
ЗТ и КТ, осадков в период проведения ПГЗ (1967-1983 гг.). Fig. 4. The comparison of calculated and virtual atmospheric precipitations at the PA and $\mathrm{ChOT}_{2}$ during AHP activities (1967-1983).

Они представлены в таблище 6, анализ которой позволил заключить, что в результате увеличения суммарных значений выше перечисленных параметров на ЗТ отмечается уменьшение трехмесячных (май-июль) средних сумм осадков, а на $\mathrm{KT}_{2}$ - их увеличение. Вероятность обнаружения колеблется в пределах 33-92\% от всех взятых случаев в заданном интервале значений этих параметров.

Например, с увеличением количества израсходованных изделий «Эльбрус-2» («Эльбрус-4») от 100 (300) до 500 (1000) на ЗТ отмечается в среднем уменьшение трехмесячных сумм осадков от 15 до 20\%, а на $\mathrm{KT}_{2}$ - их увеличение от 22 до $33 \%$. Аналогичная картина отмечается и тогда, когда эффект воздействия рассматривается в зависимости от значений $\Sigma H_{\mathrm{B}}, \Sigma \lg Z$ и $\Sigma \Delta \tau$.

Таким образом, в результате проведения в Южной Грузии ПГЗ с применением комбинированного метода воздействия отмечается перераспределение осадков из 3Т на $\mathrm{KT}_{2}$. Эффект перераспределения проявляется на расстояниях не более 40-50 км. В районах Центральной части Южной Грузии протяженность 3 Т по направлению смещения градоопасных и градовых ячеек не превышает 50 км. Поэтому максимальный эффект увеличения осадков будет отмечаться на $\mathrm{KT}_{2}$, имеющей протяженность не более 50 км.

Полученные результаты могу быть объяснены, исходя из физических основ, заложенных в комбинированном методе борьбы с градом ЗакНИГМИ 
Таблица 6. Оценка влияния пгз на режим трехмесячных сумм осадков (май-июль 1967-1983 гг.) ЗТ и КТ и вероятности их обнаружения (знаменатель) в зависимости от значений радиолокационных параметров и параметров воздействия: $\Sigma \lg Z, \Sigma \mathrm{H}_{\mathrm{B}}, \Sigma \mathrm{N} \cup \Sigma \Delta \mathrm{T}$

Table 6 . The evaluation of ahp influence on the mode of three-months' precipitations total (may-july 1967-1983) at the PA and ChOT ${ }_{2}$ of South Georgia (nominator) and their acquisition probability (denominator) depending on the values of radar and impact parameters: $\Sigma \operatorname{lgZ}, \Sigma \mathrm{H}_{\mathrm{B}}, \Sigma \mathrm{N}$ AND $\Sigma \Delta \mathrm{T}$

\begin{tabular}{l|llll}
\hline Территория & \multicolumn{3}{|l}{$\sum \mathrm{H}_{\mathrm{B}}$, Км/Mес. } & \\
\hline & $\leq 200$ & $201-400$ & $401-600$ & $>600$ \\
\hline $3 \mathrm{~T}$ & $\frac{10(9)}{56(5)}$ & $\frac{-9(20)}{70(14)}$ & $\frac{-14(14)}{79(11)}$ & $\frac{-14(8)}{75(6)}$ \\
\hline $\mathrm{KT}_{2}$ & $\frac{2(9)}{56(5)}$ & $\frac{21(20)}{75(15)}$ & $\frac{21(14)}{50(7)}$ & $\frac{30(8)}{75(6)}$ \\
\hline
\end{tabular}

$\sum \lg Z$, мec. $^{-1}$

\begin{tabular}{l|cccc}
\hline & $\leq 40$ & $41-120$ & $121-200$ & $>200$ \\
\hline $3 T$ & $\frac{36(6)}{33(2)}$ & $\frac{-14(24)}{62(8)}$ & $\frac{-17(15)}{87(13)}$ & $\frac{-21(6)}{83(5)}$ \\
\hline $\mathrm{KT}_{2}$ & $\frac{8(6)}{67(4)}$ & $\frac{23(24)}{75(18)}$ & $\frac{19(15)}{67(7)}$ & $\frac{44(6)}{100(6)}$ \\
\hline
\end{tabular}

$\frac{\text { Эльбрус-4 }}{\text { Эльбрус-2 }} N_{\text {изд, }}$ мес..$^{-1}$

\begin{tabular}{l|llll}
\hline & $\frac{\leq 101}{\leq 201}$ & $\frac{101-300}{201-600}$ & $\frac{301-500}{601-1000}$ & $\frac{>500}{>1000}$ \\
\hline $3 T$ & $\frac{47(6)}{33(2)}$ & $\frac{-15(23)}{70(16)}$ & $\frac{-20(12)}{92(11)}$ & $\frac{-18(10)}{90(9)}$ \\
\hline $\mathrm{KT}_{2}$ & $\frac{17(6)}{33(2)}$ & $\frac{22(23)}{70(16)}$ & $\frac{33(12)}{92(11)}$ & $\frac{22(10)}{60(6)}$ \\
\hline ST & $\leq \Delta \mathrm{T}, 4 . / \mathrm{Mec}$. & & & $>11,6$ \\
\hline $\mathrm{KT}{ }_{2}$ & $\frac{16,0}{44(4)}$ & $\frac{-9(11)}{45(5)}$ & $\frac{-10(11)}{82(9)}$ & $\frac{-14(20)}{80(16)}$ \\
\hline & $\frac{-9(7)}{67(6)}$ & $\frac{38(11)}{91(10)}$ & $\frac{17(11)}{82(9)}$ & $\frac{23(20)}{60(12)}$ \\
\hline
\end{tabular}

[3]. Он основан, главным образом, не на увеличении начальной концентрации зародышей градин, а на изменении условий их роста.

Введение в теплую часть облака гигроскопического реагента в количестве 500 г/км ${ }^{3}$ или $0,1 \pi^{-1}$ (такие концентрации наблюдаются при естественном развитии облаков и осадков) способствует существенному усилению 
конденсационно-коагуляционного роста капель, образовавшихся на частицах соли; перераспределению осадков в пользу теплой части облака и преждевременному их выпадению.

Они в нижней тропосфере, за счет выравнивания температур облака и окружающего воздуха, способствуют некоторому уменьшению сил плавучести и не дают облаку достичь стадии своего максимального развития, то есть отмечается преждевременное разрушение облака, приводящего к уменьшению выпадающих из них осадков на ЗТ.

Не исключена возможность попадания некоторых крупных частиц из теплой части облака в область отрицательных температур [3].

Дальнейшее введение в переохлажденную и обедненную влагой часть градовой ячейки ЧКР AgI в количестве 20-80 г/км ${ }^{3}$ и/или 100-400 л ${ }^{-1}$ воздуха на литр воздуха, по-видимому, может вызвать перезасев, так как для образования естественных осадков требуется более $10 \pi^{-1}$.

Дополнительное количество скрытой теплоты кристаллизации, выделенное в результате замерзания облачных и дождевых капель на искусственных ядрах кристаллизации, способствует [9] увеличению восходящих потоков; выносу ледяных частиц в наковальню облака, откуда струйными течениями они могут быть перенесены на значительные расстояния, то есть отмечается перераспределение выпадающих на земле осадков из зоны воздействия на $\mathrm{KT}_{2}$, расположенной с подветренной от $3 \mathrm{~T}$ стороны.

\section{Оценка изменения режима осадков Восточной Грузии методом конкуренции}

На рисунке 2 представлены $\mathrm{KT}_{1}$ и $3 \mathrm{~T}$ Восточной Грузии, каждая из которых занимает площадь 650 тыс. га, а их протяженности по ведущему потоку не превышают 130 км. Из анализа рисунка 2 следует, что в годы отсутствия ПГЗ (апрель-октябрь 1953-1965 гг. - числитель) по сравнению с годами ее проведения (апрель-октябрь 1967-1978 гг. - знаменатель) на КТ в $100 \%$ от всех взятых случаев ( 8 случаев) отмечается увеличение $\Delta K_{4}$, а на ЗТ - их уменьшение на $87,5 \%$ от всех взятых случаев ( 8 случаев).

Рассмотрим статистические характеристики сезонных значений $\Delta R_{4}$ и $\Delta K_{4}$ на $\mathrm{KT}_{1}$ и ЗТ Восточной Грузии до начала (1953-1965 гг. - числитель) и в период проведения (1967-1978 гг. - знаменатель) ПГЗ (табл. 8).

Из таблицы видно, что в годы проведения ПГЗ по сравнению с предшествующими воздействию годами на $\mathrm{KT}_{1}$ отмечается увеличения $\Delta R_{4}$ на 49 мм $/$ мес. и $\Delta K_{4}-$ на $0,4 \%$, а на $3 T$ - увеличение $\Delta R_{4}$ на 18 мм $/$ мес. и уменьшение $\Delta K_{4}$ на $5,5 \%$.

Оценка влияние ПГЗ на режим ССО ЗТ Восточной Грузии проводилась также с привлечением следующего уравнения прямолинейной регрессии [4]:

$$
R_{\text {зТ }}=1,38 R_{\mathrm{KT}}-23
$$


Таблица 7. Результаты сравнения статистических характеристик значений сезонных (IV-X) $\Delta \mathrm{R}_{4}$ (Mм/Mес.) и $\Delta \mathrm{K}_{4}(\%)$ CCO на $\mathrm{KT}_{1}$ и Восточной Грузии до начала (1953-1966 гг. - числитель) и в период проведения (1967-1983 гг. - знаменатель) ПГЗ

Table 7. The results of comparison of statistical characteristics of seasonal (IV-X) $\Delta \mathrm{R}_{4}(\mathrm{~mm} / \mathrm{mth})$ and $\Delta \mathrm{K}_{4}(\%)$ values of apt at $\mathrm{ChOT}_{1}$ and pa of East Georgia before the beginning (1953-1966 - numerator) and during ahp activities (1967-1983 denominator)

\begin{tabular}{|c|c|c|c|c|c|c|c|c|}
\hline \multirow[t]{2}{*}{ Территория } & \multicolumn{2}{|l|}{$\mathrm{CcO}$} & \multicolumn{2}{|c|}{$\begin{array}{l}\text { Среднеквадратическое } \\
\text { отклонение }\end{array}$} & \multicolumn{2}{|c|}{$\begin{array}{l}\text { Коэфрфициент } \\
\text { вариации }\end{array}$} & \multicolumn{2}{|c|}{$\begin{array}{l}\text { Модульный } \\
\text { коэфрфициент }\end{array}$} \\
\hline & $R_{4}$ & $\Delta R_{4}$ & $\sigma$ & $\Delta \sigma$ & $v$ & $\Delta v$ & $K_{4}$ & $\Delta K_{4} \cdot 100 \%$ \\
\hline $\mathrm{KT}_{1}$ & $\frac{415}{464}$ & 49 & $\frac{92}{71}$ & -21 & $\frac{0,19}{0,12}$ & $-0,07$ & $\frac{0,860}{0,864}$ & 0,4 \\
\hline 3Т & $\frac{550}{568}$ & 18 & $\frac{142}{107}$ & -35 & $\frac{0,18}{0,15}$ & $-0,03$ & $\frac{1,148}{1,093}$ & $-5,5$ \\
\hline
\end{tabular}

Расчеты показали, что в годы проведения ПГЗ на ЗТ Восточной Грузии отмечается уменьшение ССО на $11,2 \%$, что находится в пределах ошибок измерения уравнения регрессии $(10,6 \%)$. Расхождение между рассчитанными и фактически измеренными ССО становится существенным при $\alpha=0,1, n_{1}=n_{2}=12$ и $T_{0,1}>T_{\text {экпा }}=17$.

Для оценки естественной изменчивости $\Delta K$ на $\mathrm{KT}_{1}$ и $3 \mathrm{~T}$ Восточной Грузии было проведено дополнительное исследование. Из 30 метеостанций и постов было отобрано 12, в том числе: 6 метеостанций (Цхинвали, Гори, Мухрани, Душети, Пасанаури и Тианети) на КТ 1 и 6 метеостанций (Ахмета, Телави, Сагареджо, Гурджаани, Цнори и Лагодехи) на ЗТ (рис. 1).

Далее для $\mathrm{KT}_{1}$ и ЗТ до $\left(1936-1947^{*}, 1953-1964 *\right.$ гг.) и в период проведения (1967-1978 гг.) ПГЗ были рассчитаны значения $K_{4}$ и $\Delta K_{4}$. Расчеты представлены в таблице 8, согласно которой на $\mathrm{KT}_{1}$ в 1936-1947 гг. по сравнению с 1953-1964 гг. отмечено уменьшение $\Delta K_{4}$ на $1,0 \%$, а на ЗТ - его увеличение на $1,9 \%$.

Таким образом, естественная изменчивость $\Delta K_{4}$ до проведения ПГЗ составляла, соответственно $-1,0$ и $1,9 \%$.

Сравнение значений $K_{4}$ и $\Delta K_{4}$ периодов без ПГЗ (1936-1947, $1953-$ 1964 гг.) со значениями $K_{4}$ и $\Delta K_{4}$ с периодом ПГЗ (1967-1978 гг.) показывает, что значения $\Delta K_{4}$ на 3 Т уменьшились на 7,5 и 9,4\%, а на $\mathrm{KT}_{1}-$ увеличились на 4,0 и $5,0 \%$. Таким образом, амплитуда естественного хода $\Delta K_{4}$ на этих территориях достигает $2,9 \%$, а в период проведения ПГЗ $-11,5$ и $14,4 \%$.

Увеличение $\Delta K_{4}$ на $\mathrm{KT}_{1}$ и его уменьшение на ЗТ могут быть объяснены, исходя из физических соображений, заложенных в методе конкуренщии [15, 17]. Данный метод: 
Таблица 8. Результаты сравнения значений $\mathrm{K}_{4}$ и $\Delta \mathrm{K}_{4}$ на $\mathrm{KT}_{1}$ и $3 \mathrm{~T}_{\text {Вос- }}$ точной Грузии до начала (числитель) и в период проведения (знаменатель) ПГЗ

Table 8. The results of comparison of $\mathrm{K}_{4}$ and $\Delta \mathrm{K}_{4}$ values at $\mathrm{ChOT}_{1}$ and pa of east Georgia Before the beginning (numerator) and during (denominator) ahp activities

\begin{tabular}{|c|c|c|c|}
\hline \multirow[t]{2}{*}{ Период осреднения } & \multirow[t]{2}{*}{ Территория } & \multicolumn{2}{|c|}{ Модульный коэфффициент } \\
\hline & & $k$ & $\Delta K \cdot 100 \%$ \\
\hline \multirow[t]{2}{*}{$\frac{1936-1947}{1953-1964}$} & $\mathrm{KT}_{1}$ & $\frac{0,901}{0,891}$ & $-1,0$ \\
\hline & 3Т & $\frac{1,081}{1,100}$ & 1,9 \\
\hline \multirow[t]{2}{*}{$\frac{1936-1947}{1967-1978}$} & $\mathrm{KT}_{1}$ & $\frac{0,901}{0,941}$ & 4,0 \\
\hline & 3Т & $\frac{1,081}{1,006}$ & $-7,5$ \\
\hline \multirow[t]{2}{*}{$\frac{1953-1964}{1967-1978}$} & $\mathrm{KT}_{1}$ & $\frac{0,891}{0,941}$ & 5,0 \\
\hline & 3Т & $\frac{1,100}{1,006}$ & $-9,4$ \\
\hline
\end{tabular}

* - - 1936-1947 гг. и 1953-1964 гг. производственная защита с/х культур от града на $\mathrm{KT}_{1}$ и ЗТ Восточной Грузии не проводилась.

шей градин в зоне аккумуляции (крупнокапельной фракции) в 100-1000 раз и на изменении условий их роста, что в дальнейшем существенно может повлиять на уменьшение запаса жидкокапельной влаги и размера градин в ОВ 1-4-й категорий;

- базируется на физических преставлениях о механизме образования града, сложившихся в ВГИ [16], согласно которым скорость восходящих потоков с высотой увеличивается, достигает максимального значения $\left(W_{m}\right)$ и в дальнейшем уменьшается.

Если $W_{m}$ меньше скорости гравитационного падения $V_{\Gamma}$, то есть $W_{m}<$ $V_{\Gamma}<10 \mathrm{M} / \mathrm{c}$, то зона аккумуляции не формируется $\left(V_{\mathrm{K}}-\right.$ критическая скорость гравитационного падения разбрызгивающих капель). Если в области переохлажденной части ОВ 1-4-й категорий $W_{m}<V_{\mathrm{K}}$, то некоторые капли начинают замерзать, которые становятся зародышами града и, в дальнейшем быстро растут за счет коагуляции с крупными каплями в зоне аккумуляции [7]. 
Выделение скрытой теплоты кристаллизации при замерзании капель способствует дополнительному увеличению скорости восходящих потоков $(W, \mathrm{~m} / \mathrm{c})$, высоты верхней границы $\left(H_{\mathrm{B}}, \mathrm{\kappa м}\right)$, мощности переохлажденной части ( $\Delta H_{\Pi}$ км) и максимальной абсолютной водности $\left(q_{m}\right.$, г/м $\left.{ }^{3}\right)$ OB 1-4-й категорий; выносу частиц капель и крупы OB 1-4-й категорий из зоны воздействия в наковальню по направлению движения ведущего потока, так как скорости их гравитационного падения меньше скорости восходящих потоков $\left(V_{\Gamma}=4 \mathrm{~m} / \mathrm{c} \leq W_{m}>4 \mathrm{v} / \mathrm{c}\right)$, что может повлиять на уменьшение осадков на ЗТ и их увеличение на $\mathrm{KT}_{2}$ [7].

\section{Оценка изменения режима осадков методом шокового воздействия в северной части региона Центрального Кавказа}

Оценка изменения режима осадков в исследуемой северной части региона Центрального Кавказа ПГЗ (рис. 2), проводилась не по данным $\mathrm{HMC}$ и постов Южной и Восточной Грузии, а по данным радиолокационных наблюдений, проводимыми полуавтоматизированным радиолокатором МРЛ «АСУ МРЛ», установленного в г. Ставрополе Ставропольского края [7]. Радиус его действия достигал 250 км. С юго-запада он охватывал территории ВС Краснодарского края, считающейся для ЗТ Ставропольского края $\mathrm{KT}_{1}$, расположенной с наветренной от нее стороны, а с севера-востока - территории районов Ставропольского края, расположенной с подветренной от ЗТ стороны $\left(\mathrm{KT}_{2}\right)$.

Для оценки влияния ПГЗ на режим осадков $\mathrm{KT}_{1}, 3 \mathrm{~T}$ и $\mathrm{KT}_{2}$ привлекались суммарные значения кинетической энергии падающего града $\left(\Sigma E_{\mathrm{K}}\right.$, Дж/м $\left.{ }^{2}\right)$ и радиолокационной отражаемости $(\Sigma Z, \mathrm{dBZ})$, прямо или косвенно характеризующих количество осадков, выпадающих на поверхность земли.

На рис. 5а и 5б в период проведения ПГЗ (май-сентябрь 2004-2005 гг.) дается сезонное распределение значений $\Sigma E_{\mathrm{K}}$ на $\mathrm{KT}_{1}$, ЗТ и $\mathrm{KT}_{2}$. Из этих рисунков видно, что на ЗТ значения $\Sigma E_{\mathrm{K}}$ изменяются от 10 до 400 Дж/м ${ }^{2}$, а на $\mathrm{KT}_{1}$ и $\mathrm{KT}_{2}$ - от 10 до 2000 Дж/м² и более, то есть, в результате проведения ПГЗ на $\mathrm{KT}_{1}$ и $\mathrm{KT}_{2}$ отмечается увеличение значений $\Sigma E_{\mathrm{K}}$ от 400 до 2000 Дж/м ${ }^{2}$ и более.

Таким образом, наблюдаем перераспределение значений $\Sigma E_{\mathrm{K}}$ из зоны воздействия на $\mathrm{KT}_{2}$, косвенно характеризующих значения количества выпавших на земле осадков.

Анализировались также распределения суммарных месячных значений $\Sigma E_{\mathrm{K}}$, и $\Sigma Z$ [11]. Анализ полученных результатов в период проведения ПГЗ также подтвердил перераспределение значений $\Sigma E_{\mathrm{K}}$ и $\Sigma Z$ из $3 \mathrm{~T}$ на $\mathrm{KT}_{1}$ и $\mathrm{KT}_{2}$ (рис. 6). Оно вызвано не синоптическими процессами и физико-географическими условиями исследуемого региона, а влиянием объективного метода шокового воздействия, разработанного автором этой статьи $[8,10,12]$, в основу которого были положены следующие физические представления 


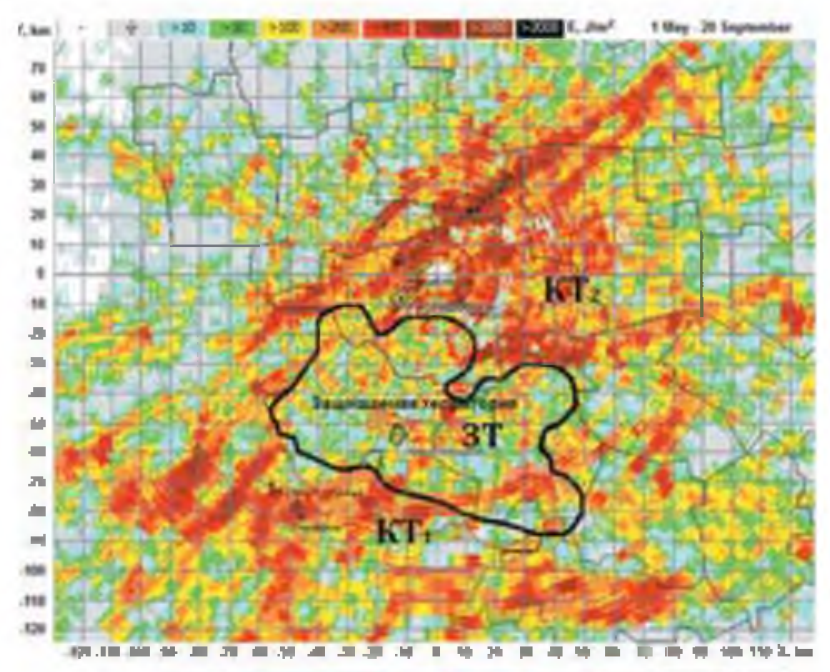

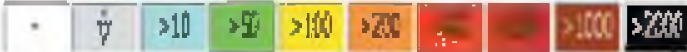

a) Май-сентябрь 2004 г., $E_{\mathrm{K}}\left(Д \ldots / \mathrm{M}^{2}\right)$

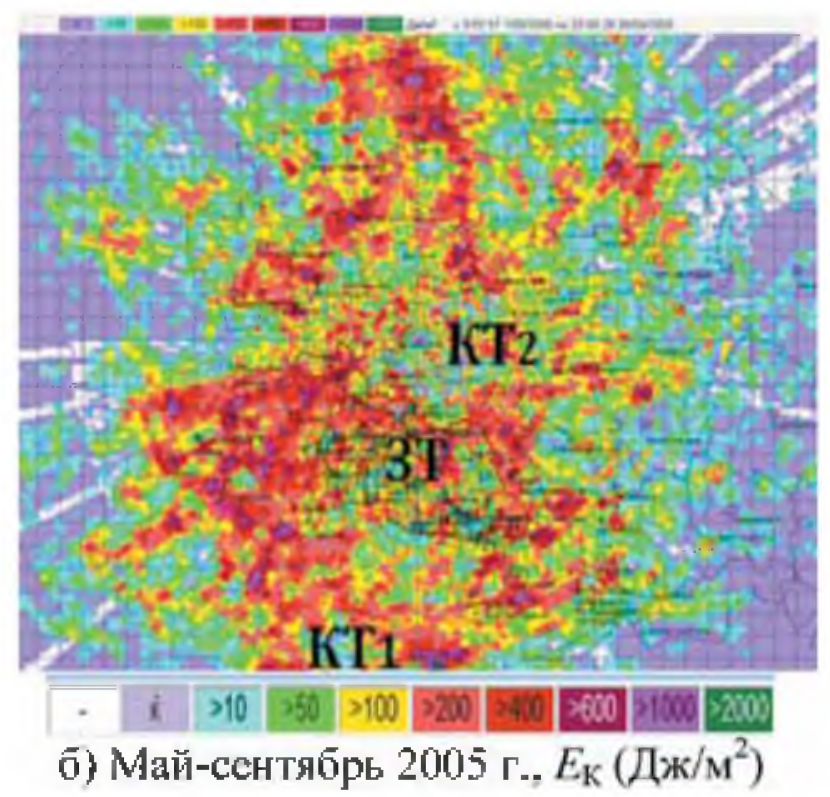

Рис. 5.

Карты сезонного распределения суммарной кинетической энергии града (а) и радиолокационной отражаемости (б) на 3Т, КТ ${ }_{1}$ и КТ 2 северной части региона Центрального Кавказа.

Fig. 5. The maps of season distribution of hail total kinetic energy (a) and radar reflection (b) at the $\mathrm{PA}, \mathrm{ChOT}_{1}$ and $\mathrm{ChOT}_{2}$ of the northern part of the Central Caucasus region. 
1. В неустойчивой атмосфере отдельные импульсы нисходящего потока, создаваемые в ООС искусственно вызванными осадками, могут значительно усилиться, приводя к ослаблению скорости восходящих потоков, питающих ОВ 3-4-й категории по пути предполагаемой траектории их перемещения в сторону 3Т. В результате, к подступам 3Т Ставропольского края, отмечается прерывание града из ОВ 3-4-й категорий ни за счет непосредственного воздействия на ОВ 3-4-й категорий, а за счет воздействия на ОOC, развивающихся на ЗТ со стороны вторжения градовых облаков.

2. При 1-4-х кратных засевах на ЗТ объемов зон роста града и будушего градообразования ОВ 1-4 категорий оптимальным количеством ПГР, определяемым в момент начала воздействия экспериментальным путем и приводящими к положительным результатам в ПГЗ, продолжительности воздействий $\left(\Delta t_{\mathrm{B}}\right.$, мин) должны быть меньше:

- п продолжительности процесса градообразования в пространственно фиксированном объеме градового облака $\left(\Delta t_{\Gamma}\right)$ изменяющегося от 4 до 25 мин, в среднем - от 10 до 12 мин [1, 10, 12];

- $\quad$ времени проявления эффектов воздействий $\left(\Delta t_{\ni}\right)$ полученного для различных технологий засева и достигающих в OB 1-й категории 3-5 мин, ОВ 2-й категории 6-9 мин, ОВ 3-й категории 13-19 мин, ОВ 4-й категории 20-25 мин [8, 12]: $\Delta t_{\mathrm{B}} \leq \Delta t_{\Gamma} \leq \Delta t_{\ni}$.

Выполнение выше перечисленных условий в зоне роста града и будущего градообразования способствует дополнительному увеличению:

количества израсходованных ПГР и интенсивности их
стрельбы;
мгновенной скрытой теплоты кристаллизации при замерза-
нии капель, а следовательно и скорости восходящих пото-
ков $(W, \mathrm{M} / \mathrm{c}) ;$
высоты верхней границы OB $1-4-$ й категории $\left(H_{\mathrm{B}}, \mathrm{\kappa м}\right)$ и ра-
диолокационной отражаемости $(Z, \mathrm{dBZ}) ;$
выносу частиц капель и крупы из зоны воздействия в на-
ковальню по направлении движения ведущего потока $[8-$
$10,12]$.

Перечисленные факторы стали причиной уменьшения осадков на $3 \mathrm{~T}$ и их увеличения на $\mathrm{KT}_{2}$.

При анализе и обобщении результатов собственных исследований и литературного материала работ по ПГЗ и искусственному регулированию осадков, проводимых в различных регионах мира, в том числе, и регионе Цент- 


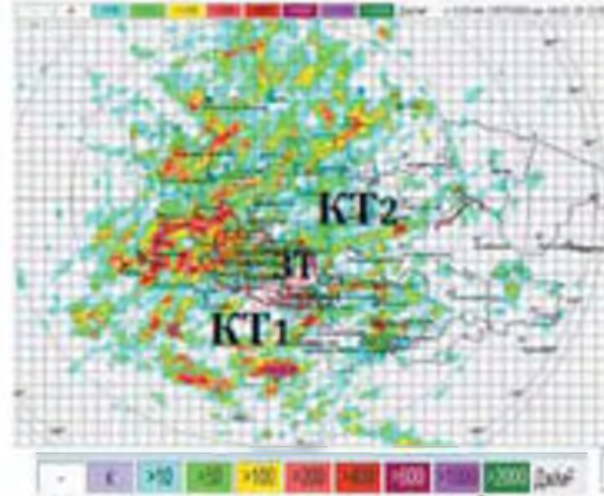

a) Июль $2005 \mathrm{r} ., E_{\mathrm{K}}\left(\right.$ Дж/ $\left./ \mathrm{M}^{2}\right)$

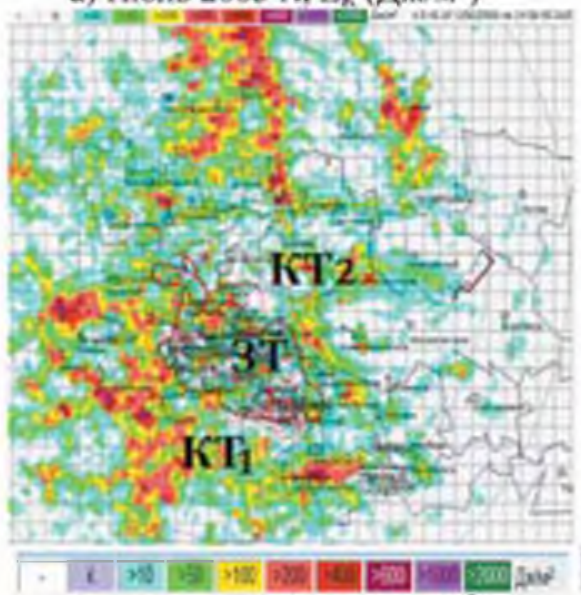

а) Авгует 2005 г., $E_{\mathrm{K}}$ (Дж/ $\left./ \mathrm{M}^{2}\right)$

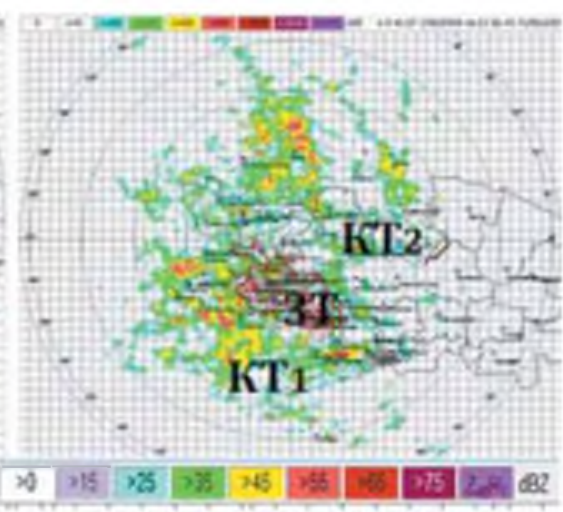

б) Июль 2005 г., Z (dBZ)

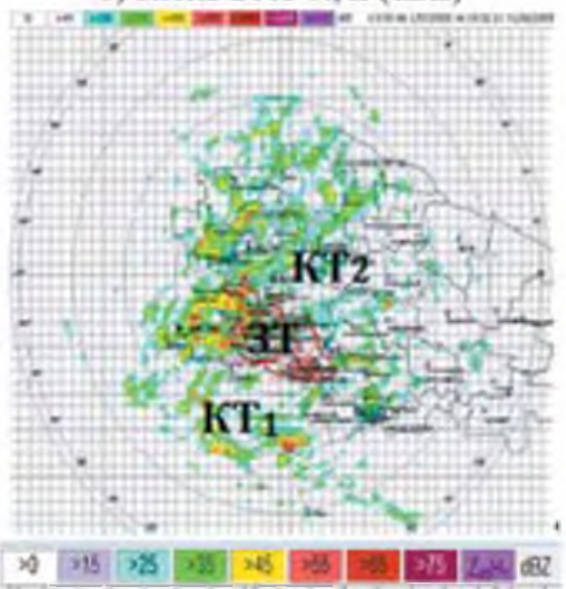

6) Август 2005 г., Z (dBZ)

Рис. 6.

\begin{abstract}
Карты сезонного распределения суммарной кинетической энергии падающего града (а) и радиолокационной отражаемости (б) на $3 \mathrm{~T}_{,} \mathrm{KT}_{1}$ и К $\mathrm{KT}_{2}$ северной части региона Центрального Кавказа.
\end{abstract}

Fig. 6. The maps of season distribution of falling hail total kinetic energy (a) and radar reflection (b) at the $\mathrm{PA}, \mathrm{ChOT}_{1}$ and $\mathrm{ChOT}_{2}$ of the northern part of the Central Caucasus region

рального Кавказа, выявлена зависимость количества осадков, выпавших на ЗТ и $\mathrm{KT}_{2}$ от норм расхода реагента, продолжительности воздействия и величины их площадей. При больших дозировках реагента и значениях пло-

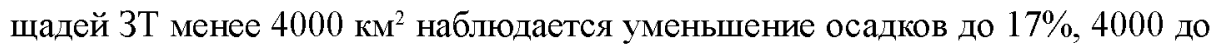
$7000 \mathrm{\kappa м}^{2}$ - уменьшение или увеличение осадков до $6 \%$ и более $7000 \mathrm{\kappa м}^{2}-$ увеличение осадков от 15 до $40 \%$. 
$403 \%$

30

20

10

0

$-10$

$-20$

Рис. 7.

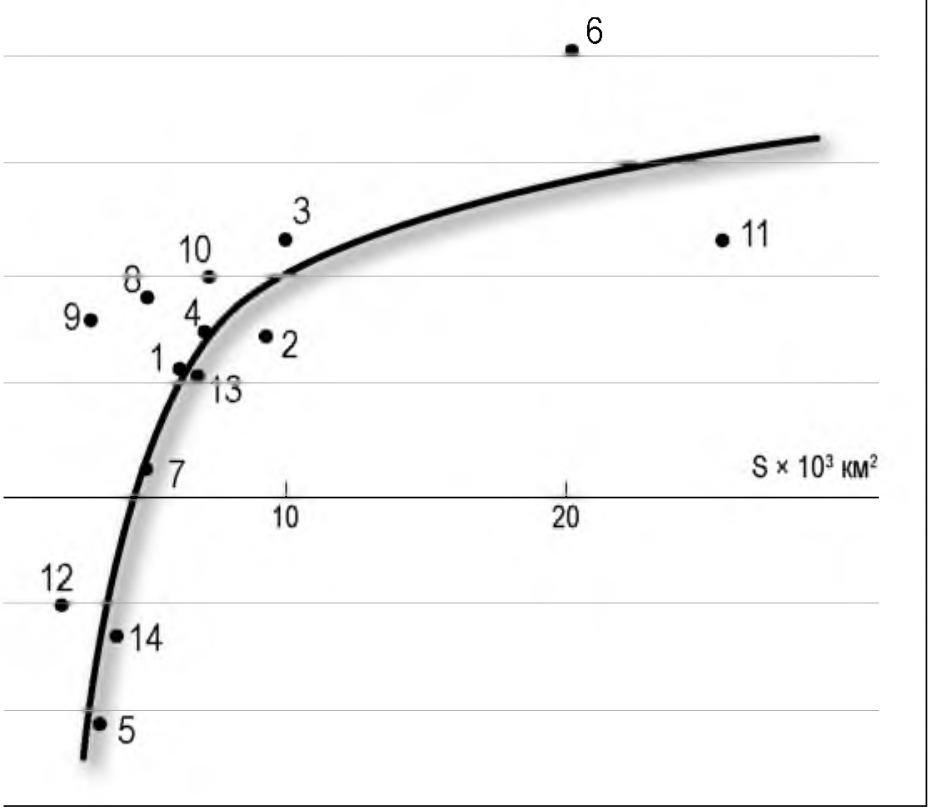

Зависимость эффекта воздействия от площади ЗТ при проведении ПГЗ и Проектов.

Fig. 7. The dependence of influence impact on the area of PA when carrying out AHP activities and Projects.

Результаты представлены на рисунке 7 и взяты из различных литературных источников регионов мира:

Северный Кавказ;

Закавказье;

Северная Дакота;

Южная Дакота;

Ферганская долина;

Канада;

Молдавия;

Краснодарский край;

Крым;

Испания;

Сербия;

Болгария;

13. Кахети;

14. Нижний Картли. 


\section{Выводы}

1. Противоградовая защита, проводимая в регионе Центрального Кавказа комбинированным методом, методами конкуренции, УПО и шокового воздействия в апреле-мае, июнеиюле, августе-сентябре и апреле-июне на ЗТ сопровождается уменьшением осадков соответственно на $13,1,16,2,8,1$ и $14,2 \%$, а на $\mathrm{KT}_{2}$ - их увеличением соответственно на 14,9 , $21,2,9,2$ и $20,2 \%$.

2. При одних и тех же значениях суммарных радиолокационных параметров ( $\Sigma H_{\mathrm{B}}$ и $\left.\Sigma \lg Z\right)$ с увеличением суммарных норм расхода противоградовых изделий штук на ЗТ отмечается уменьшение количества осадков от 15 до $20 \%, \Sigma N$ («Эльбрус-4»/ «Эльбрус-2») от 101-300/201-600 до 3013500/601-1000, а на $\mathrm{KT}_{2}$ - их увеличение от 22 до 33\%. При этом увеличение баланса влаги на $\mathrm{KT}_{2}$ на 7 и $13 \%$ превышает те потери, которые отмечаются на $3 \mathrm{~T}$.

Полученные результаты могут быть учтены при планировании и проведении ПГЗ и ИРО с помощью противоградовой техники.

\section{Библиографический список}

1. Абшаев М.Т., Климовская Л.Н. О влиянии противоградовых работ на интенсивность и количество осадков // Труды ВГИ. 1976. Вып. 33. С. 123-131.

2. Абшаев М.Т., Абшаев А.М., Малкарова А.М., Барекова М.В. Руководство по организации и проведению противоградовых работ. Нальчик: Печатный двор, 2014. 500 с.

3. Бартишвили Я.Т., Надибаидзе Г.А. Бегалишвили Н.А., Гудушаури Ш.Л. К физическим основам метода ЗакНИГМИ борьбы с градом // Труды ЗакНИГМИ. 1978. Вып. 67(73). С. 73-82.

4. Бартишвили И.Т. и др. Оценка влияния противоградовой защиты на режим осадков защищаемых и контрольных территорий Южной и Восточной Грузии / Бартишвили Я.Т., Ватьян М.Р., Капанадзе Н.И., Кирвалидзе Ц.Д., Мирианашвили Н.И., Морчиладзе Н.С., Одикадзе М.Я. // Труды ГГО. 1986. Вып. 497. C. 63-68.

5. Бартишвили Я.Т., Ватьян М.Р., Капанадзе Н.И., Одикадзе М.Я. I Исследование влияния противоградовой защиты на режим осадков Центральной части Южной Грузии // В кн.: Материалы Всесоюзного семинара по фризике образования градовых процессов и активных воздействий на них. - М.: Гидрометеоиздат, 1988. C. $118-123$. 
6. Ватиашвили М.Р., Капанадзе Н.И., Одикадзе М.Я. / Перераспределение осадков в районах Восточной Грузии при воздействии на градовые процессы // Труды Всесоюзного семинара «Активные воздействия на градовые процессы и перспективы усовершенствования льдообразующих реагентов для практики активных воздействий», 1991. С. 243-251.

7. Ватиашвили М.Р, Калов Х.М. Размеры трансформации спектра размера гидрометеоров при естественном развитии и активном воздействии на конвективные процессы» // Труды Всесоюзного семинара «Активные воздействия на градовые процессы и перспективы усовершенствования льдообразующих реагентов для практики активных воздействий». М.: Гидрометеоиздат, 1991. C. 131-136.

8. Ватиашвили М.Р., Джангуразов Х.Х., Кассиров В.П. Способ активных воздействий на градовые процессы. Патент РФ на изобретение №2321871, заявка № 2006 121792, а 01 G 15/10/ 2007.

9. Ватиашвили М.Р. Влияние фазовых переходов воды на параметры облаков и облачных систем, развивающихся в естественных условиях и подвергшихся воздействию частицами льдообразующих реагентов // Радиолокационная метеорология и активные воздействия. Сборник статей ГГО, посвященный памяти В.Д. Степаненко. 2012. С. 162-177.

10. Ватиашвили М.Р. Метод прерывания града на подступах защищаемой территории со стороны вторжения градовых облаков // Наука. Инновации. Технологии. 2016. №4. С. 7-24.

11. Ватиашвили М.Р. Характеристики радиолокационной отражаемости облаков и осадков на различных длинах волн // Наука. Инновации. Технологии. 2017. №4. С. 105-118.

12. Ватиашвили М.Р. Метод прерывания града на защищаемых территориях региона Центрального Кавказа // Наука. Инновации. Технологии. 2018. №1. С. 7-22.

13. Ватиашвили М.Р. Оценка влияния на окружающую среду йодистого серебра, применяемого в противоградовой защите // Наука. Инновации. Технологии. 2018. №2. С. 7-22.

14. Ватиашвили М.Р. Обзор методов противоградовой защиты в регионе Центрального Кавказа // Наука. Инновации. Технологии. 2018. №3. С. 7-22.

15. Карцивадзе А.И., Салуквадзе Е.Г., Лапинскас В.А., некоторые вопросы методики воздействия на градовые процессы с использованием противоградовой системы «Алазани» // Труды института геофизики АН Грузии. 1975. 198 с.

16. Рунион Р. Справочник по непараметрической статистике: Современный подход / перевод с английского языка Демиденко Е.3. М.: Финансы и кредит, 1982. 198 с.

17. Сулаквелидзе ГК. Ливневые осадки и град. Л.: Гидрометеоиздат, 1967. $421 \mathrm{c}$. 
18. Сванидзе Г.Г, Бегалишвили Н.А., Ватьян М.Р., Карцивадзе А.И., Гудушаури Ш.Л. Методические указания по организации и проведению работ по искусственному увеличению осадков из конвективных облаков с помощью противоградовой техники. М.: Гидрометеоиздат, 1986. 25 с.

\section{References}

1. Abshaev M.T., Klimovskaya L.N. O vliyanii protivogradovykh rabot na intensivnost' i kolichestvo osadkov (About the influence of antihail works on the atmospheric precipitations intensity and amount) // Trudy VGI. 1976. Vol. 33. P. 123-131.

2. Abshaev M.T., Abshaev A.M., Malkarova A.M., Barekova M.V. Rukovodstvo po organizatsii i provedeniyu protivogradovykh rabot (The Manual on organizing and executing of anti-hail works). NaIchik: Pechatnyi dvor, 2014. 500 p.

3. Bartishvili Ya.T., Nadibaidze G.A., Begalishvili N.A., Gudushauri Sh.L. K fizicheskim osnovam metoda ZakNIGMI bor'by s gradom. (To the physical foundations of the ZakNIGMI method of hail control) // Trudy ZakNIGMI, Vol. 67(73), 1978. P. 73-82.

4. Bartishvili I.T. et al. Otsenka vliyaniya protivogradovoi zashchity na rezhim osadkov zashchishchaemykh i kontrol'nykh territorii Yuzhnoi i Vostochnoi Gruzii (The evaluation of anti-hail protection influence on the atmospheric precipitations mode of the protected and checkout areas of South and East Georgia) / Bartishvili I.T., Vatian M.R., Kapanadze N.I., Kirvalidze Ts.D., Mirianashvili N.I., Morchiladze N.S., Odikadze M. Ya. // Trudy GGO. 1986. Vol. 497. P. 63-68.

5. Bartishvili I.T., Vatian M.R., Kapanadze N.I., Odikadze M.Ya. / Issledovanie vliyaniya protivogradovoi zashchity na rezhim osadkov Tsentralnoi chasti Yuzhnoi Gruzii (The research of anti-hail protection influence on atmospheric precipitations mode of the Central part of South Georgia) // V kn.: Materialy Vsesoyuznogo seminara po fizike obrazovaniya gradovykh protsessov i aktivnykh vozdeistvii na nikh. M.: Gidrometeoizdat, 1988. P. 118-123.

6. Vatiashvili M.R., Kapanadze N.I., Odikadze M. Ya. Pereraspredelenie osadkov $v$ raionakh Vostochnoy Gruzii (Reallocation of the atmospheric precipitations in the East Georgia area when influencing on hailing) // Trudy Vsesoyuznogo seminara "Aktivnye vozdeistviya na gradovye protsessy i perspectivy usovershenstvovaniya l'doobrazuyushchikh reagentov dlya praktiki vozdeistvii». M.: Gidrometeoizdat, 1991. P. 243-251.

7. Vatiashvili M.R., Kalov Kh.M. Razmery transformatsii spectra razmera gidrometeorov pri estestvennom razvitii i aktivnom vozdeistvii na konvektivnye protsessy (Transformation range of hydrometeor size spectrum when natural developing and active influencing on convection processes) // Trudy Vsesoyuznogo seminara "Aktivnye vozdeistviya na gradovye protsessy i perspektivy usovershenstvovaniya l'doobrazuyushchikh reagentov dlya praktiki aktivnykh vozdeistvyi». M.: Gidrometeoizdat, 1991. P. 131-136. 
8. Vatiashvili M.R., Dzhangurazov Kh.Kh., Kassirov V.P. Sposob aktivnykh vozdeystviy na gradovye protsessy (The way of active influences on hail processes) // Patent RF na izobreteniye №2321871, zayavka № 2006 121792, a 01 G 15/10/ 2007 (Patent of the Russian Federation for invention №2321871, application № 2006 121792, a 01 G 15/10/ 2007).

9. Vatiashvili M.R. Vliyanie fazovykh perekhodov vody na parametry oblakov i oblachnykh system, razvivayushchikhsya $v$ estestvennykh usloviyakh i podvergshikhsya vozdeistviyu chastitsamy l'doobrazuyushchikh reagentov (The influence of water phase transition on the parameters of clouds and cloud systems developing in natural conditions and having been affected by particles of ice-forming reagents) // Radiolokatsionnaya meteorologiya i aktivnye vozdeistviya. Sbornik statei GGO, posvyashchionnyi pamyati V.D. Stepanenko. 2012. P. 162-177.

10. Vatiashvili M.R. Metod preryvaniya grada na podstupakh zashchishchaiemoy territorii so storony vtorzheniya gradovykh oblakov (Method of interrupting hail at the approach lanes of the protected area from the direction of hail clouds invasion) // Nauka. Innovatsii. Tekhnologii (Science. Innovation. Technologies). 2016. №4. P. 7-24.

11. Vatiashvili M.R. Kharakteristiki radiolokatsionnoi otrazhaemosti oblakov i osadkov na razlichnykh dlinakh voln (Radar reflection characteristics of clouds and precipitations at different wave lengths) // Nauka. Innovatsii. Tekhnologii (Science. Innovation. Technologies). 2017. №4. P. 105-118.

12. Vatiashvili M.R. Metod preryvaniya grada na zashchishchaemykh territoriyakh regiona Tsentralnogo Kavkaza (The method of hail breaking on the protected areas of the Central Caucasus region) /I Nauka. Innovatsii. Tekhnologii (Science. Innovation. Technologies). 2018. №1. P. 7-22.

13. Vatiashvili M.R. Otsenka vliyania na okruzhayushchuyu sredu iodistogo serebra, primenyaemogo $v$ protivogradovoi zashchite (The evaluation of the influence of argentum iodide on the environment used in anti-hail protection) // Nauka. Innovatsii. Tekhnologii (Science. Innovation. Technologies). 2018. №2. P. 7-22.

14. Vatiashvili M.R. Obzor metodov protivogradovoy zashchity $v$ regione Tsentralnogo Kavkaza (The review of methods of anti-hail protection in the Central Caucasus region) // Nauka. Innovatsii. Tekhnologii (Science. Innovation. Technologies). 2018. №3. P. 209-226.

15. Kartsivadze A.I., Salukvadze T.G., Lapinskas V.A. Nekotorye voprosy metodiki vozdeistviya na gradovye protsessy s ispolzovaniem protivogradovoi sistemy «Alazani» (Some issues of method of affecting hail processes with anti-hail system «Alazani») // Trudy instituta geofiziki AN Gruzii. 1975. 198 p.

16. Runion R. Spravochnik po neparametricheskoi statistike: Sovremennyi podkhod (Reference book on non-parametrical statistics: 
Modern approach / the translation from English by Demidenko E.Z.). M.: Finansy i credit, 1982. 198 p.

17. Sulakvelidze G.K. Livnevye osadki i grad (Cloud bursts and hailing) L.: Gidrometeoizdat, 1967. 421 p.

18. Svanidze G.G., Begalishvili N.A., Vatian M.R., Kartsivadze A.I., Gudushauri Sh.L. / Metodicheskie ukazaniya po organizatsii i provedeniyu rabot po iskusstvennomu uvelicheniyu osadkov iz konvektivnykh oblakov s pomosh'yu protigradovoy tekhniki. (Study guide on arranging and carrying out activities on artificial increasing of atmospheric precipitations from convective clouds by means of antihail equipment). M.: Gidrometeoizdat, 1986. 25 p.

Рукопись поступила в редакцию 10.04.2019 г.

Принята к публикации 01.06.2019 г.

\section{Сведения об авторе}

Ватиашвили Михаил Рубенович. Кандидат географических наук, доцент, Грузинский государственный научно-технический центр «Дельта» министерства обороны Грузии.

Грузия, г. Тбилиси, ул. Габриеля Салоса, 191.

Научный консультант по проектам.

\section{About the author}

Vatiashvili Mikhail Rubenovich. Candidate of geographical sciences The senior lecturer Georgian state scientific and technological center «Delta» Ministries of Defence of Georgia Scientific consultant for projects.

+995 598-341-451.

Mivv123@mail.ru.

191 Monk Gabriel Salos Ave. 0144 